\title{
Turning a Blind Eye
}

\section{An Exploration of Non-Visual Game Design}

\author{
Hunter Mulder \\ Victoria University of Wellington
}

2017

A thesis submitted to the Victoria University of

Wellington in fulfillment of the requirements for the degree of Masters of Design Innovation 
"Recognising the need is the primary condition for design" Charles Eames 


\section{Abstract}

This thesis presents a non-visual game for visually impaired people which uses technology designed for interacting with Virtual Reality (VR) environments to provide a tailored experience that focuses on touch and sound. According to the world health organisation, $0.03 \%$ of the world's population is blind. However, according to the world's largest computer game market, Steam, only $0.0003 \%$ of games published in its catalog are designed for visually impaired people. This discrepancy shows that there is a clear issue in regards to the representation of visually impaired people in the design of computer games.

By examining existing computer games designed for visually impaired people, a set of design criteria was established in order to improve the experience delivered to a visually impaired player in a computer game. This was accomplished by adopting existing

VR input methods such as tracked motion controllers and head tracking technology in order to track a player's motion and position in space. The experience reacts to the position and placement of the player's head and hands by using outputs such as spatialized audio combined with haptic feedback. A game was then designed using these inputs and outputs that would allow a visually impaired player to use their sound and proprioceptive senses to navigate and interact with the environment.

Visually impaired people were interviewed in regards to their experience and thoughts upon computer games. The game experience was then be tested by the same group of visually impaired players and user feedback was then integrated into an iterative design process. The final outcome of this thesis is a game experience that takes into account the needs and requirements of the underrepresented audience of visually impaired people who wish to enjoy computer games as a medium. 


\section{Acknowledgments}

First and foremost I would like to thank the play testers for so graciously giving up their time to aid me in testing this game and the BLENNZ staff for all their help in facilitating this.

I would like to thank my supervisors Leon Gurevitch and Byron Mallet for their continued support and mentorship throughout this process.

Thanks to Michael Wightman for providing voice acting for this project.

Finally I would like to thank my family for their ongoing support. 


\section{Contents}

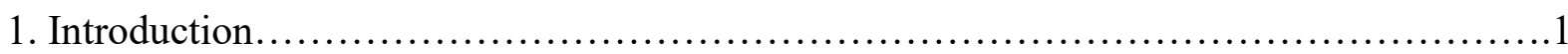

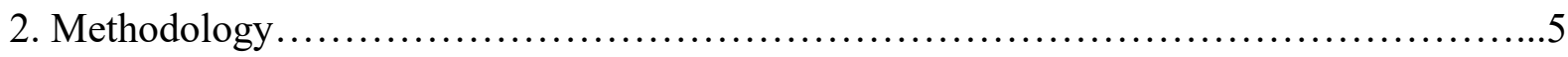

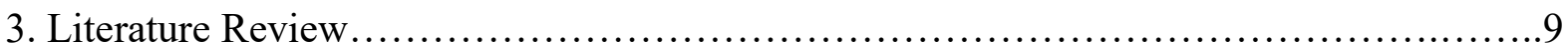

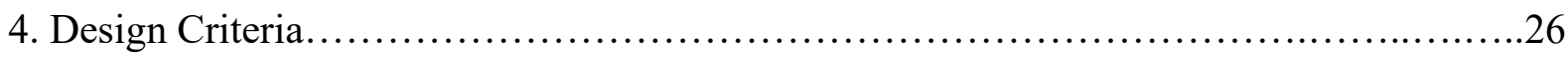

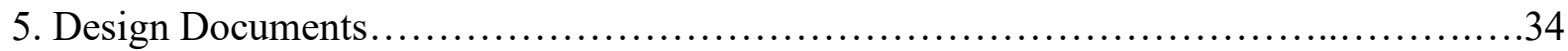

6. Design Process Documentation...............................................42

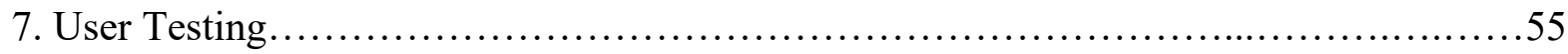

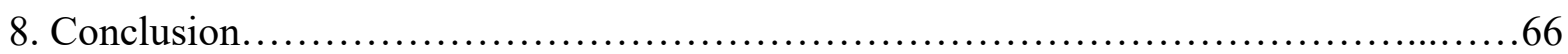




\section{Chapter 1}

Introduction 
"Dispite its popularity, the majority of electronic games are designed for people with perfect cognition, sensory and physical development"

Cheiran, Nedel Pimenta, 2011 
Computer games are a widely accessible medium for leisure and education and, with few exceptions, they cater to almost all demographic groups and ability levels. The widespread uptake of personal computers and smart devices globally (United Nations, n.d.) has made computer games readily available to most communities throughout the world to the extent that they are now firmly ensconced in our modern "cultural landscape".

However, there is one group that still lacks access to computer games, which is the blind and visually impaired. Computer games rely heavily on the visual interface to provide information and context that enables a player to play the game. While there are some mainstream computer games that can be played by those with a level of visual impairment (The Blind Spot, 2014), the clear majority cannot and there are very few games designed specifically to enable play with no use of visual output at all. This severely restricts access to a large part of modern culture for the significant group of blind and visually impaired people.

According to the World Health Organisation (Visual Impairment and Blindness, 2014, para 1), as of 2014 there are approximately 285 million people worldwide classified as visually impaired (blind or low vision), out of a total global population of 7.3 billion (The World Population Prospects: 2015 Revision, 2015, para 1).

This lack of access to games suitable for the blind can be quantified by examining the catalogue of Steam, the world's largest online distributor of computer games. Steam contains over 7000 computer games and in a close examination of Steam's catalogue (searching on keywords such as "blind", "visually impaired", and "non-visual") only two games could be found that were designed specifically with visually impaired players in mind - A Blind Legend (Dowino, 2016) and Grail to the Thief (For All to Play, 2014). With visually impaired people comprising approximately $0.04 \%$ of the global population and only two games out of a catalogue of 7,000 games $(0.0003 \%)$ available for the visually impaired on the world's largest online distributor, there is clearly a large scale underrepresentation of games being offered for the blind. This is likely to be a consequence of the significant design challenges that designing computer games for the visually impaired presents. 
In this thesis, I intend to design and create a non-visual computer game that utilises virtual reality technologies and, in doing so, identify the key aspects of successful non-visual game design. The game itself will make use of the Oculus Rift head mounted display (HMD) and Oculus Touch Controllers as the main input method, allowing for real time head tracking within a threedimensional soundscape. This game will utilise audio and haptic feedback only; no visuals will be used. This should then provide broad access to those with all levels of visual impairment and blindness. This will be achieved by initially undertaking secondary research focused on game design, sound design, and design for the visually impaired, as well as the current state of non-visual computer games. The information gained from this will be used to create design criteria that identify what constitutes a successful non-visual game. This criteria will then be used to form an evaluation matrix that prototype ideas can be run through to assess their suitability as a non-visual game. 
Chapter 2

Methodology 
"Nothing is particularly hard if you divide it into small jobs" Henry Ford 
Initially I utilised document analysis to gain a firm foundation upon which I could construct this thesis. Given that non-visual game design is a broad and relatively unexplored area of research I chose to divide my analysis into three separate categories; game design, sound design, and design for the blind.

Considering the output from this thesis is first and foremost a computer game, it is clear that I would need research into what constitutes a "good" game, and the criteria for developing one. I was able to derive a great deal of information from Raph Koster's book A Theory of Fun for Game Design (Koster, 2005).

My second area of research was specific to sound design. With the output of this thesis being nonvisual, its success is almost wholly reliant on the context and the quality of the constituent sounds. Expertise in sound design allows me to create better and clearer soundscapes and aural locations, increasing the overall quality of the final output.

My third and final area of document analysis was in specifically designing for the visually impaired. It is important that I account for any differences, other than sight, that visually impaired people may have compared to sighted people when designing this non-visual game. As such, knowledge of how visually impaired people interact with the world and technology is imperative.

Having undertaken a full literature review and developed a set of design criteria for the non-visual game, the next step is the actual prototyping of the game. For this I used operational prototyping, a method of prototype development outlined in the paper Operational Prototyping: A New Approach (Davis, 1992). Operational prototyping is comprised of two prototyping methods, evolutionary prototyping and throwaway prototyping, used concurrently. Evolutionary prototyping is the practice of creating an initial prototype, then refining and iterating upon that prototype until it is at a finalised and working state. Throwaway prototyping is almost the exact opposite; a prototype is made, knowledge is gained through the act of prototyping itself, and the prototype is discarded so the process may begin again 
The process of operational prototyping begins with the creation of a base prototype through evolutionary design, iterating and refining until a satisfactory baseline is achieved. With this basic prototype in place, features can be implemented quickly, then discarded if they are unsatisfactory, in the style of throwaway prototyping. If the feature is deemed worthwhile, it can be permanently implemented into the prototype in a more suitable standard. This now becomes the new baseline and the process can begin anew.

Once a final product was developed, I used playtesting methodology as outlined by Katherine Isbister and Noah Schaffer in their book Game Usability: Advancing the Player Experience (2008). This involves, primarily, having users play sections, or the entirety of your game. Some form of data collection then takes place. There are a variety of ways that data collection can take place (Questionnaires, Interviews, Monitoring player input) in playtesting. I chose to conduct face to face interviews with each user after they had completed a short section of gameplay. I chose this more indepth data collection as it was better suited to the smaller number of visually impaired volunteers available to me. With a small sample size (four) I could not gain statistically significant quantitative data. Another important consideration was that the playtesters were all visually impaired and one to one interviews would be the most appropriate form of feedback for them. This qualitative feedback also gave significant opportunity to gain in depth detail regarding aspects of the game the players found difficult, as well as aspects of the game they enjoyed. I had the participants play a 5-10 minute segment of the game, then interviewed them on the experience. The testing had to take place one user at a time as I only had access to a single station for the users to play the game at, but this allowed observation of the gameplay which was very useful as the VR gameplay can be quite physical.

I also undertook a short interview with each player before the playtesting started to gather data on each of the users' prior experience with computer games and technology. This data helped me to contextualise the feedback and information collected in the playtesting sessions. 


\section{Chapter 3}

Literature Review 
"The human brain is mostly a voracious eater of patterns..... Games are just exceptionally tasty patterns to eat up"

Koster 2005 
For most people, computer games offer a level playing field, regardless of age or gender or ability levels. However, for some, computer games are a difficult, even impossible medium to engage with. It is for these people that the medium of computer games must be expanded and adjusted, be that by creating input methods and feedback mechanisms that can be easily used by those with physical disability or by creating games that can be enjoyed by those with mental disabilities. I am looking at the development of computer games for the blind and visually impaired. My research has been in three main areas: Audio design, Game design, and Designing for the blind. I undertook research in these three areas to gain a better understanding of what constitutes a successful game that is able to be played by people with visual impairment. I then compared several existing non-visual games to the results of my research to discover what may be lacking.

\subsection{Sound Design}

Audio design is a major part of contemporary computer games. It can be used not only to provide context to a game system, but is also used as a means of conveying crucial game information to the player. Examples of this are speech as instruction, sounds to highlight mechanics such as jump or shoot, or trying to locate and decipher the cause of a sound. In the design of non-visual games this background usage of audio as an informative medium becomes the primary function of audio. When visuals are removed from a game, there are very few options left for conveying information to the player, with the most comprehensive tool remaining for the designer being audio. To fully understand how audio might be used to achieve these ends in game design, we must first look to general sound theory.

\section{The Auditory Field}

The auditory field is the space in which audio is created and perceived; much as an artist paints onto a canvas, audio is "painted" onto the auditory field (Ihde, 2007). Auditory field is discussed in Don Ihde's book Listening and Voice: Phenomenologies of Sound (2007).

Ihde describes sound as being both encompassing and directional at once. What this means is that the auditory field is surrounding; a human can hear a sound from any direction. However, particularly cacophonous sounds can fill the entirety of this space; this is the encompassing nature of the auditory field. The directional nature of the auditory field comes from a human's amazing ability to echolocate. The human brain can pick up on minute changes in pitch, 
tone, and arrival time between sounds hitting each ear, then process that information to ascertain the direction and potential distance the sound came from.

So, if sound is both directional and encompassing, how might we understand what makes a sound encompassing and what makes a sound directional. Ihde argues that it is all a matter of musicality; a sound being particularly musical or rhythmic will appear to be more encompassing than some isolated, mundane sound. However, it is not only the nature of the sound that influences this, but the attitude of the listener. Ihde puts forward an idea he calls the "musical mood", which is a state one can put oneself into in which one can hear non musical sounds in a musical way and experience their encompassing nature.

"The hammering from next door is heard from next door. The sparrow's song in the garden presents itself from the garden. But if I put myself in the 'musical attitude' and listen to the sound as though it were music, I may suddenly find that it's... directionality, while not disappearing, recedes to such a degree that I can concentrate on it's surrounding presence." (Ihde, 2007)

This idea of the attitudes of the listener changing the properties of the sound was first put forth by film sound theorist Michel Chion in The Sound Studies Reader (Chion, 1994). He describes this as the three modes of listening.

\section{Three Modes of Listening}

Chion posits that there are three main modes of listening: causal, semantic, and reduced. Chion describes causal listening as "the most common but also the most easily influenced and deceptive mode of listening". It is the mode in which the listener is trying to identify the cause of the sound, listening for audio clues about the direction, distance, intent and other subtler pieces of information the sound has. This mode of listening is the basis of human echolocation and therefore forms the basis of many non-visual games, using the causal listening style to convey information to the player. The next style of listening that Chion discusses is semantic listening, which is potentially the simplest listening style to understand, but the most complex in its nature. Semantic listening is listening for codes and languages in sound. Semantic listening is used when listening to human speech or deciphering Morse code. 
Causal listening is often employed alongside semantic listening. "We hear at once what someone says and how they say it. In a sense, causal listening to a voice is listening to it semantically" (Ihde, 2007). Finally, there is reduced listening. This mode of listening is related to Ihde's idea of a "musical attitude". It is listening to the sound itself, stripped of context or meaning. It comes up most frequently in listening to music, as finding sound free of context, sound that does not spark our innate need to identify potential risks, is rather rare in day-to- day life. However, just as Ihde spoke of hearing the musical nature of non-musical sounds, one can utilise reduced listening on any sound. It is the process of hearing the sound as a sound rather than as the cause of it. "The hunter intent on bagging his game misses the musical sonority of the birdsong, not because it isn't there, but because it is the direction and location of his prey that motivates him" (Ihde, 2007)

\section{Types of Sounds}

Much as Chion defined types of listening, Johnny Friberg and Dan Gärdenfors of the Stockholm International Toy Research Centre have defined several types of sounds in their paper Audio Games: New Perspectives on Game Audio (Friberg,

Gardenfors, 2004) that outlines the process of designing several games for the Tactile Interactive Media project. They describe these types of sound as: avatar, object, character, ornamental and instructional sound. These sound types are quite specific to games and game design rather than to general audio design.

Avatar sounds are sounds created by the player's avatar activity, such as walking, shooting, or bumping into objects. These serve as feedback devices, letting the player know that their input has been registered by the game system and the corresponding action is taking place.

Object sounds indicate the presence of objects. In a practical sense, they can warn of objects the player needs to know the location of.

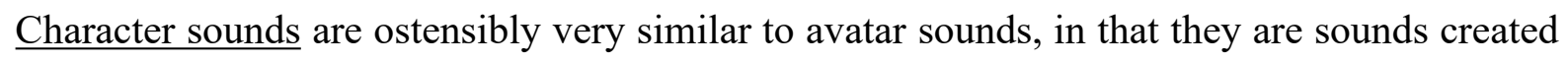
by non-player characters. However, they serve a purpose much closer to that of object sounds, informing the player of non-player characters in the area around them. 
Ornamental sounds serve no obvious gameplay purpose. They are there simply to add atmosphere or tone to the game, for example ambient music.

Instructional sounds are semantic instructions, usually speech, that serve to very directly inform the player of aspects of the game system.

A game does not necessarily need to use all of these different sounds. In fact, a game could be created using only avatar and object sounds.

\section{Earcons}

Earcons are a simple idea first put forward by D. A. Sumikawa in the article Guidelines for the integration of audio cues into computer user interfaces (Sumikawa, 1985). Sumikawa discusses earcons in the context of computer interfaces. They are used to refer to the sounds that a computer makes to alert its user to something within the game. Earcons are essentially audial icons, sounds that have no inherent meaning but a meaning is applied to it that the user learns. In game design, they are essentially the same thing; any sound that the player does not immediately recognise and assign a meaning to, but one which has a meaning assigned to it by the game system. Earcons are used extensively in existing non-visual games as they allow for very specific information to be delivered to the player very easily. For example, in the game Papa Sangre by Somthin' Else (2013) the end of each level is identifiable by a distinctive chime that the game establishes early on. This allows the designers to tell the player exactly where the level exit is through the use of a single sound asset, as opposed to using something like semantic instructional sounds.

\subsection{Design for the Visually Impaired}

In designing computer games for the visually impaired, it is important to consider the differences in how sighted and non-sighted people interact with objects and systems in their day-to- day lives. The primary difference, rather obviously, is the visually impaired person's lack of sight. This forces them to adopt new strategies for activities such as navigating spaces, interfacing with computers, and locating objects or destinations. The core set of these abilities comes under the name of Orientation and Mobility (O\&M) (Jacobson, 1993). Orientation and Mobility is the name given to the set of skills a blind or visually impaired person might need in order to navigate and move through the spaces in which they live. 


\section{Basics of Orientation and Mobility}

The ability to move about and travel safely and without assistance is one of the cornerstones of independence for people who are blind or visually impaired.

Orientation and mobility is a core skill set for visually impaired people to be able to move about in the world unassisted, and is a set of basic skills that comes together to give the ability to navigate spaces. The core of these skills are: Sensory development, self-protective techniques, cane usage, and mapping strategies.

Sensory development is essentially the enhancement of one's remaining senses. This may seem obvious; however, this extends beyond just hearing and touch. Visually impaired people are taught to use senses such as visual memory, which can be used to help visualise and create mental pictures of spaces one visits often. Even the mundane senses are taught to be used in new ways; for example, one might identify certain areas based on the way the wind moves through them, a breeze could indicate an open door or an air conditioner that is located at a certain position.

Self-protective techniques are skills that visually impaired people employ to prevent themselves from walking into objects, tripping over, or otherwise injuring themselves. The most common of these is the use of one's hand to detect objects in front of oneself. Cane usage is the skill of utilizing the "white cane" that many blind people use. These skills involve using the cane as a self-protective device to detect objects in front of the user and learning to identify the nature of the surface that the cane strikes based on the sound it makes. Mapping techniques are the techniques employed to aid in navigation of a larger space. Like the visualisation component of sensory development, this is about building a cognitive map of a space.

\section{Orientation and Mobility in Games}

So, what clues do these O\&M techniques provide in terms of designing non-visual games? Examining the O\&M techniques gives a simulacrum of how visually impaired people experience and interact with the world, providing knowledge on how visually impaired people gain spatial information from the surrounding world. This gives a starting point for designing a game system that can be utilised by a visually impaired person. Sensory development identifies that visually 
impaired people get most of their information via sound, using human sound localisation to perceive the area around them and the location of objects within that area. This

means that sound design is the most crucial aspect in conveying information in a non-visual game. Proper utilization of all three listening styles, earcons, and sound types is the cornerstone of making a non-visual game playable, but it is not the only matter. Understanding the differences in how visually impaired people understand space is also crucial.

Sighted people construct their cognitive map using one of two spatial modes: route model and map model. The route model is based on linear recognition of spatial features... blind people tend to explore and navigate spaces mainly using the route model. (Lahav, 2014)

What this means is that when understanding and navigating space, visually impaired people tend to understand the space as a list of instructions e.g. go forward through the door and turn left. As such if given an open map based game many would end up confused or lost. The route based navigational system shows up in many existing non-visual games, from A Blind Legend's (Dowino, 2016) semantic instructions on where the player needs to go, to Papa Sangre (Somethin' Else, 2010) laying down a pseudo breadcrumb trail of earcons. In the designing of non-visual games these differences in how the world is perceived must be constantly remembered and implemented into the design of the game.

\section{Orientation and Mobility Training in Games}

The use of gamified virtual environments to train visually impaired people O\&M skills was a topic explored by Seki and Sato (2011). They posited that a virtual teaching environment for O\&M skills could be just as effective as a real teaching environment. They conducted an experiment by creating an audio only virtual reality rig. They would then get sighted people, untrained in O\&M, to enter the VR space blindfolded. The rig would be playing "various sounds such as vehicles, stores, environmental noise, etc." (Seki \& Sato, 2011) and the subjects were then instructed to perform a series of activities, including: locating and facing certain sounds, detecting the distance of certain objects via sound, and walking a parallel line. This training was conducted daily for five days. Once the five days of training had been completed, the test subjects were compared to other sighted people who had been through a similar amount of training via traditional methods and a control group that had no training in a real environment. They found that those trained in a virtual environment were superior in walking straight lines to both those trained in a real environment and 
the control group, and their stress levels were equal with those trained in real environments, much lower than the untrained control group. This suggests that virtual environments can be as effective, if not more so, than traditional O\&M teaching environments.

\subsection{Game Design}

\section{What is a Game?}

Definition of the word 'game' is a fairly broad topic, with arguments about the difference between games, toys and sports. In his book A Theory of Fun for Game Design Raph Koster puts forward this simple deconstruction of games, "the human brain is mostly a voracious eater of patterns... Games are just exceptionally tasty patterns to eat up" (Koster, 2005). Koster is saying that games are essentially examples of what we see in real life, abstracted to make the underlying patterns more appealing to our brains. "Games are puzzles to solve, just like everything else in life... We learn the underlying parts, grok them fully, and then file them away so that they can be rerun as needed" (Koster 2005). In the above quote Koster used the

term "grok" (or "grokking") which is a term first used in the science fiction story Stranger in a Strange Land by Robert Heinlein (1961). "It means to understand something so thoroughly that you have become one with it and even love it." (Koster 2005). Koster relates grokking with muscle memory, although he deems the term muscle memory less than accurate. He sees grokking as the end goal of most standard game systems, to teach the player everything the game has and to keep the player playing until there is nothing new to be learned from the game.

In a technical sense a game is a game system with a narrative surrounding it. Take chess for example, a fairly abstract system about pieces moving on a board, wrapped up in a narrative of medieval warfare. A game system is the fundamental workings of a game, the mechanics, dynamics, and aesthetics of it all. Game systems tend to be highly mathematical and very difficult to interpret on their own. The narrative serves as a buffer to the raw mathematical nature of game systems. Much like a word problem in mathematics, giving context and meaning to a mathematical problem can make it far more approachable.

As discussed above, mechanics, dynamics and aesthetics are crucial components of a game. This game design concept, put forward in the paper Mechanics, Dynamics, Aesthetics: A formal 
Approach to Game Design and Game Research (Hunicke, Leblanc, Zubek, 2004), breaks game design into three categories, the mechanics of the game, the dynamics they create, and the aesthetics that show through. This is described as a flow; mechanics create dynamics, dynamics create aesthetics. The mechanics are the fundamental building blocks of the game, (eg running, shooting, matching sets of objects); the most basic parts. Dynamics are born from the interplay between these mechanics.These are comparable to what game designer Ben Cousins calls "ludemes" (Cousins, 2004), basic packets of gameplay e.g. get to the other side, visit every location. These dynamics coming together form the aesthetics, which are the 'fun' of the game.

The aesthetics of a game are the sensations that the player experiences when playing the game. There are 8 different aesthetics of play according to (Hunicke, Leblanc, Zubek, 2004), :

- sensation

- fantasy

- narrative

- challenge

- fellowship

- discovery

- expression

- submission.

I will discuss these further later in this section.

\section{What Makes Games Fun?}

Koster argues that "what makes games fun" is very simple - games are fun because they teach us things (Koster, 2005). The brain loves to learn. Learning and adapting is what helps us to survive; learning to hunt kept us fed, learning to build shelter kept us protected from the elements. This is true of most animals. Play is prevalent in many animal species (Oliveria, Rossi, Silva, et al. 2010). There have even been signs that show larger brained animals tend to play more (Iwaniuk, Nelson, Pellis, 2001). So, what do games teach us? Koster claims that "Games almost always teach us tools for being the top monkey or top tribe of monkeys" (Koster, 2005); that play is an evolutionary trait that teaches us necessary skills for survival. 
Specifically, games were to teach us tools for survival in a pre-civilised world. "Many things we have fun doing are in fact training us to be better cavemen" (Koster, 2005); from learning sports such as archery to running marathons, we hold onto these antiquated skills because they still appease that primal caveman part of our brain. Koster goes on to point out that not all games dwell in the caveman era. Games and their teachings have evolved along with humans, with a good example of this being games about farming. The game "Mancala" is a game about farming, about sowing seeds and harvesting and thus receiving more seeds. The point is this game is about very hands-on farming, working the land. If I were to look at a modern game about farming, for instance "Farmville" (Zynga, 2009), it plays out very differently. Farmville is much more a game about business and resource management, teaching lessons relating to modern farming processes.

\section{Types of Fun}

Fun is something of a rigid term, one that can be problematic for games and game design. Thus, many game designers have adopted other terms to take the place of fun when referring to games. The aesthetics of play were defined to be: sensation, fantasy, narrative, challenge, fellowship, discovery, expression, submission (Hunicke, Leblanc, Zubek, 2004). These terms do not all allude to a sensation that we would describe as fun; a more appropriate term might be engagement. Fun could be thought of as a form of engagement and is present in Koster's list of types of enjoyment:

- Fun is the act of mastering a problem mentally

- Aesthetic appreciation isn't always fun, but it's certainly enjoyable

- Visceral reactions are generally physical in nature and relate to physical mastery of a problem

- Social status signals of various sorts are intrinsic to our self-image and our standing in a community (Koster, 2005)

There is overlap between these two different frameworks of engagement. Sensation (Hunicke, Leblanc, Zubek, 2004), and aesthetic appreciation (Koster, 2005) are essentially the same thing, reveling in the sensory joys of a game such as music or visuals. One might also argue that narrative fits in here as well. Narrative is less visceral than sensation, but it is similar in that it has very little to do with the game system, existing only in the narrative context surrounding it.

Koster's notion of fun does not have a direct connection into the aesthetics of play, resting somewhere amongst challenge, submission, and discovery. Challenge and discovery are rather selfexplanatory; however, submission is a little more complex. Submission relates to Csikszentmihalyi's 
(1990) idea of flow. Flow is the state of mind wherein you reach a state of oneness with the game; it is also called immersion. Koster contextualises flow within his framework, stating that flow comes at the end of fun, once you have learned all the game has to teach, and the game should then become boring. However, it is at this point that the player fully masters the game and it is no longer a teaching or training tool, but a source of comfort, a safe place in which the player is in complete control (Koster, 2005).

Social status signals relate to several of the aesthetics of play: fellowship, expression and arguably fantasy. Fellowship is about conquering a great task through teamwork and cooperation. Our caveman brains like this as, for a tribal species, cooperation is key to survival. While fellowship does not place the player on a higher social status than the other players, it does prove to the player comrades that the player is a capable and valuable member of the tribe, thus proving their social value. Expression is about showing off one's personality or identity through the game's mechanics, be it through a customizable character, or gameplay that the player can adapt to their personal choices. Fantasy isn't as clear cut as the previous aesthetics. Fantasy is allowing the player to experience something that they would otherwise not be able to, be it slaying monsters or playing Premier League football. Not all fantasies have to do with achieving a higher social status, but many are. Fantasy can serve as an emulation of sorts for a social status signal, giving the player a simulacrum of what life as a person further up the social ladder is like.

\section{Playability in Games}

Currently, there is no consensus on the definition of playability. (Zhu, Zhao, Fang, Moser, 2017)

While it is imperative that a game be enjoyable or compelling, it is extremely difficult for a game to be enjoyable if it cannot be played. The playability of a game will be critical to its success. However the definition of playability is not generally agreed upon with the literature.

In the paper Playability in Action Videogames: A Qualitative Design Model (Fabricatore, Nussbaum, $\&$ Rosas, 2002), research was undertaken to find an answer to the question "what do players want in videogames?". The answer to this question was intended to elucidate some criteria that would help to define playability in game design. Their approach to playability was that it was an overall 
measure of the quality of a game, stating that "playability is the instantiation of the general concept of usability determined by understanding and controlling gameplay”.

Sanchez, Simarro, Zea, and Vela (2009) instead viewed playability as player experience; the sum total of what the player experienced while interacting with the game. This view lines up somewhat with that of Fabricatore et al., as they both view playability as a measure of all aspects of the game.

Nacke et al. take a different view on playability, stating "We argue that playability is the evaluative process directed towards games, whereas player experience is directed towards players" (2009). This approach suggests that any assessment of playability is independent of the player and the player experience.

No specific literature was found regarding playability as it relates to blind users.

\subsection{Existing Non-Visual Games}

We now have an understanding of the components that make up a non-visual game - the correct ways in which to use sound, how to design for visually impaired people, and what makes a game enjoyable. We should now apply these to existing non-visual games and see how they compare to my research. 
This content is unavailable. Please consult the print version for access

Figure 3.1 Papa Sangre User Interface

Papa Sangre is a game from Somthin' Else (2010). The base premise of this game is that the player is stuck in the world of the dead, a world without sight, and must escape. The gameplay consists of locating objects in an arena via sound, touching those objects, then finding the exit to the level. This game uses sound very well, though having said that the sound is applied narrowly to the gameplay. The basis of the sound design is the use of earcons, which are used for almost all aspects in this game; the level exits, checkpoints, some of the enemies. I say some of the enemies as many of the enemies use sounds that have an inherent meaning to them. For instance, the first enemy you encounter, a sleeping hog, makes a very distinctive snoring sound that has an inherent threat to it. However, other enemies utilise sounds that are not inherently threatening, such as laughter, and as such the player must be taught that these sounds are dangerous. This teaching is done through semantic listening. At the start of each level a narrator will inform the player of the level to come and any dangers present. An interesting point is the lack of reduced listening. There is little to no ambient sound present in a majority of the levels while every sound present is an object 
or avatar sound, indicative of something in the environment. While this serves to make the causal listening easier, it makes the world seem empty and utilitarian.

The major issue I identified with this game is in the gameplay itself. As I outlined earlier, fun is largely about learning, and the lesson this game is teaching gets taught very quickly. The game is teaching the player to identify objects via audio. This is a challenge for the first few levels of the game but after this point, the lesson has been taught and the game then becomes tedious

\section{A Blind Legend}

This content is unavailable. Please consult the print version for access

Figure 3.2 A Blind Legend Cover Image

A Blind Legend is a game from Dowino (2016). The player is put into the role of a blind knight in a low-fantasy medieval England. The player must journey through large areas fighting any enemies they encounter. This game is almost a polar opposite to Papa Sangre. It trades in the small arenas for lengthy linear levels, making the game feel less claustrophobic, but limiting the potential for exploration. Another difference is the amount of ornamental sound. A Blind Legend has very rich and full soundscapes, really immersing the player in the world created by the game. The effect of this is that with so much of the audio space being taken up with ornamental sounds, reduced listening and causal listening is made much more difficult. To compensate for this, the player is given a sidekick in the form of the main character's daughter. Her job is to run ahead of the player and give semantic instructions on where the player should go. This serves to reduce much of the 
agency and challenge from the game. It becomes difficult to ascertain what the game is trying to teach the player as it leads them on a straightforward journey through a linear environment. This gameplay is broken up by the other mode of play, the swordfighting. The swordfighting is mechanically quite simple. An enemy will approach from any cardinal direction, and when they make a sound, the player can strike them. In this mode, most ornamental sounds are removed to allow for easier hearing of the approaching enemy. Once more this game taught all it had to teach before it was completed.

\section{Mudsplat}

This content is unavailable. Please consult the print version for access

Figure 3.3 - Mudsplat

Mudsplat was created by Johnny Friberg and Dan Gärdenfors of the Stockholm International Toy Research Centre for the for the Tactile Interactive Media Project (Friberg, Gardenfors, 2004). Mudsplat is by far the simplest of these three games. Mudsplat is essentially a shooting gallery; the character exists on an axis and can move from side to side within a restricted area. Monsters will appear at points on this axis and begin making sounds, the player must move to the same point on the axis as the monster and squirt it with water. Mechanically, this game works well, the sounds are distinctive, it is easy to identify where the sounds are and the ornamental sounds are immersing yet understated, meaning it does not distract from the game itself. The issue is much the same as the games above, the gameplay is far too shallow. That is to say the entertainment runs out very quickly as the game teaches all that it has to teach incredibly quickly. Mudsplat also does a poor job of 
informing the player of some aspects for example there is an object sound in the game that is some kind of earcon, but the game never tells the player what it is, what it does, or how to use it. 
Chapter 4

Design Criteria 
"You don't think your way to creative work, you work your way to creative thinking" George Nelson 
With the insights gained from the literature review, the next step in the project development is to define a set of design criteria for the creation of a successful non-visual game. Design criteria are a set of criteria that are put in place so that the efficacy of any design concept can be assessed (Rebernik, n.d). Some specific design considerations are needed for this project, the most important being that computer games are primarily a visual medium with the majority of the user interface (UI) being visual. To develop an effective non-visual game is therefore a deviation from the standard game design process and has significant and specific limitations on the design of the game. Finding non-visual methods to convey information to the user will be a critical factor in designing a successful non-visual game.

Another important consideration for the development of the game is that the creation of a computer game is usually managed by a large team, over a significant period of time. So, in this instance, the game selected should be able to be completed by a single developer in a defined design period.

The non-visual game should adhere to the following criteria:

1. Easily playable by someone with absolute vision loss - playable in its broadest sense, that is, is the game able to be played with no visual component?

2. Is achievable within the scope of this thesis

3. Provide an engaging and deep experience for the player

4. Fully utilises the positional tracking of the Oculus Rift and Oculus Touch controllers

5. Have clear and well defined sounds that provide all necessary feedback to the player

6. Make use of ornamental and instructional sounds to provide context and narrative

\section{Game Concepts}

As a starting point to selecting and developing a game concept, I began with a broad range of game options, all of which I considered could conceivably be played by a non visual player. These games varied widely in genre and complexity. This was a large list of rough, unfleshed concepts that I 
could then very quickly assess the quality of and cull if they were found unsatisfactory. To achieve this I used evaluation matrices.

\section{Evaluation Matrices}

Using the design criteria defined above, an evaluation matrix was developed to assess the suitability of each proposed game. To do this I divided the criteria into two sets; mandatory criteria and desirable criteria. As the title suggests, mandatory criteria are the criteria that a concept absolutely must adhere to before it is even considered. The mandatory criteria being that the game must be playable by someone with absolute vision loss and that the project is able to be completed within the scope of this thesis.

Running the original game concepts through the "mandatory evaluation" matrix, the majority of ideas did not meet both criteria and I was left with only three concepts. It was then important to understand more fully the detail of each of these concepts, to assess each game against the "desireable evaluation" matrix. To enable this, I developed a detailed design document for each of these concepts (see chapter below, and appendix 1.1 and 1.2). These design documents assisted with more fully understanding the strengths and weaknesses of each game concept and whether or not the game's scope was reasonable.

The first game concept (Private Eye) was a traditional adventure game, in the style of early point and click adventure games. However, it would be played from a first-person perspective. The player would play as a private investigator in a heavily film noir stylised world. The core gameplay would consist of locating objects within the world and solving puzzles. This concept ideally would use the Oculus Rift HMD, but would also work without it, and a gamepad for input.

The second concept (Terraform) was a resource management game, where the player plays as a small robot sent to terraform a planet for human inhabitants. The player would need to gather resources and use those resources to build structures that will slowly establish the planet infrastructure. This game would use the Oculus Rift HMD with a gamepad as a control method.

The third concept (MINIKIN) was also a resource management game where the player played as a deity watching over a small island nation, protecting the citizens and villages from natural disasters 
and threats. The player would be a giant, presiding over the island, and interfacing with the game via Oculus Rift HMD and Oculus Touch Controllers.

\section{Secondary Evaluation Matrix}

With these three game concepts developed, it was then necessary to refine the design selection further. For this, a secondary evaluation matrix was applied. This secondary evaluation matrix contained my "desirable" design criteria:

- $\quad$ Provide an engaging and deep experience for the player

- Fully utilise the positional tracking of the Oculus Rift HMD and Oculus Touch controllers

- Have clear and well defined sounds that provide all necessary feedback to the player

- Make use of ornamental and instructional sounds to provide context and narrative

While the initial evaluation aimed to identify those game concepts that were not suitable for blind users or were too large and complex to be undertaken within the scope of a thesis, this next evaluation step aimed to determine which concept would be "best" to select and build into a game. 
This would then require considerations of the user experience, the user interface (how effective it is) and a closer look at what developing such a game for a blind user would entail. The secondary evaluation criteria was applied to each game concept and rated on a scale from one to five (with 1 being does not meet criteria and 5 being meets criteria completely).

As the evaluation matrix, did not highlight any one game concept as being "better" than the others, more consideration was needed to determine an outcome. It was decided at this stage to undertake rapid prototyping of each concept to assess the efficacy of each design.

Figure 4.1 Secondary Evaluation Matrix

\begin{tabular}{|c|c|c|c|}
\hline & Terraform & MINIKIN & Private Eye \\
\hline $\begin{array}{l}\text { Likely to provide an engaging and deep } \\
\text { experience for the player }\end{array}$ & 4 & 4 & 4 \\
\hline $\begin{array}{l}\text { Utilises the positional tracking of the Oculus } \\
\text { Rift HMD and Oculus Touch controllers }\end{array}$ & 5 & 5 & 3 \\
\hline $\begin{array}{l}\text { Have clear and well defined sounds that provide } \\
\text { all necessary feedback to the player }\end{array}$ & 4 & 4 & 4 \\
\hline $\begin{array}{l}\text { Make use of ornamental and instructional } \\
\text { sounds to provide context and narrative }\end{array}$ & 4 & 4 & 4 \\
\hline Total & 17 & 17 & 15 \\
\hline
\end{tabular}




\section{Prototyping of the Three Options}

Private Eye

This prototype was developed very early and as such didn't follow the same method of rapid prototyping as the other two concepts. Through the prototyping process of this concept it became clear that navigating the indoor environments, that were full of furniture, proved to be very difficult. To remedy this a voice recognition system was added that would allow the player to enquire about the contents of the room. While this was successful; the issue that arose was in conveying information back to the player. When the player enquired what the room they were in contained, they would be told a list of all relevant objects in the room. However, if they enquired about the position of one specific piece of furniture, how would the game convey that information?

The first solution that I tried was to have the game tell the player where an object is relative to the room itself. For example, if a player were to ask about the wardrobe in the room they're currently in, the game would respond "It's in the northwest corner of the room". This approach worked for very simple room layouts, with objects only being in obvious positions, such as the corners or the centre of the room. The issue with this

approach was that it would severely limit the design space as it would prevent making larger and more complex rooms. As an attempt to address this issue, another method attempted was to provide the feedback to the player. Instead of giving the position of the object relative to the room, I gave it relative to the player. So when the player enquired about the position of an object, the game would tell them whether it was to their front, back, left, or right. This solved the issue; however, it was hugely imprecise and made searching for items extremely slow and frustrating.

\section{Terraform}

In prototyping Terraform just a small aspect of the game (ability to mine and transport resources, then refine or fabricate from them) was developed. It became clear that the many systems and features required for the game to function would cause a protracted development cycle that could potentially not be possible within the scope of this thesis. This was due to the interrelated nature of many of the systems within Terraform. This can be seen in the design document, with features such as mining, transport, fabrication, requisition, and building all being dependant on one another. 
MINIKIN

MINIKIN was the concept that was most easily prototyped. I constructed a basic pared down version of the game that was effectively a single village with a single prayer that would be solved by the player touching the village. This proved to be functional, however it did not prove to be very compelling. This was mainly due to the massive lack of decision making required in the prototype, the gameplay of this basic prototype essentially broke down into a cycle of the player hearing a sound and then moving their hand to the one position of the village. To remedy this, and attempt to emulate the fun of the completed game, more villages were added to the game. The end result of this change was that the prototype became more challenging and far more fun.

\section{Concept Selection}

After the prototyping it became clear that MINIKIN was the design concept that would best meet the requirements of the project, this was due to the fact that the MINIKIN prototype showed by far the most promise of the three. While both of the other concepts had significant merit, Terraform was likely to push the development time to unrealistic levels, and Private Eye had significant IU and navigation issues that would have had to been addressed. 


\section{Chapter 5}

Design Documents 
"If you can't explain it simply, you don't understand it well enough" Albert Einstein 
As discussed prior to the prototyping each game, a design document was developed for each game.The MINIKIN design document is detailed below, the Terraform and Private Eye design documents are contained in appendix (Appendix 1.1 and 1.2).

\section{MINIKIN: Design Document}

This document was developed at the outset of the design process in August 2016 and identifies a wide scope of detail detail possible within the game. The finished game has been significantly reduced in its scope from that of this document.

\section{Game Description}

MINIKIN is a "god-game", based around protecting several villages from incoming threats such as volcanoes, tornadoes and earthquakes.

\section{Functional Specifications}

\section{Core Gameplay}

The player exists as an extremely large physical entity overlooking an entire island full of villages. The island's size will be dictated by the Oculus play area; a large play area will allow for a large game space, a small play area allowing gameplay at "arms length". The main gameplay loop will be identifying an issue, locating the issue, and resolving the issue. For example, one of the villages may be praying for rain to water their crops, so that village will start producing a sound to indicate that. The player will need to identify this sound, identify the location of the sound, then perform the necessary gesture to summon a raincloud for them.

The game's difficulty will increase as the game progresses. When the player first begins the game, there will only be 1-3 villages to look after, but as the game goes on, these villages will expand and make colonies, creating new villages that will require attention.

The more villages there are, the more likely it is that a village will become heathens. Heathen villages will attack nearby friendly villages and must be converted. To convert a village you must make the villagers fear you, which is achieved by smiting them or inciting plagues.

The game will not have a win condition; it will serve rather as a high-score, play until you lose, game. As such the playtime will fluctuate heavily from player to player. It should remain fairly brief 
however, say 5-10 minutes. The fail state occurs once the player has allowed 3 villages to come to ruin.

\section{Game Flow}

Actions the player can perform are

1. Prevent hazard: Plug up volcano, disperse tornado, battle beast etc.

2. Aid village: Summon rain, cure disease, bless festivals, etc.

3. Convert heathen village: Lightning strikes, plague of locust, etc.

\section{Characters:}

- Village Elders: Each village has an elder that can be picked up by the player. If the player raises the elder to their ear, they will be able to listen to the elder. If the village is currently praying for something, the elder will clarify specifically what the village is praying for. Note that this is not the primary method of identifying prayers, each prayer will produce it's own specific sound and the elder is to be used as a fallback.

\section{Gameplay Elements}

There are several elements that the player will be required to pay attention to regularly:

- Village Health: Each village on the island has a health total of 3. Any time the player fails to accomplish the task of a certain village, that village will lose one health point. Health points cannot be recovered.

- Natural Disasters: Natural disasters will occur throughout the game, these will need to be taken care of or any village they come into contact with will be damaged. There are three forms of natural disaster, each with it's own solution:

- Volcano, this requires the player to hold their Oculus controller overtop of where the volcano sound is emanating for 3 seconds; 
- Tornado, this requires the player to shake an Oculus controller back and forth to create a gust of wind that will disperse the tornado, but if the gust of wind hits a village for more than 5 seconds, that village suffers damage;

- Earthquake, which requires the player to slam both Oculus controllers in a downwards motion to counteract it.

- Village Prayers: Villages will ask the player to do things for them, where failing to do so will either result in that village losing health, or becoming a heathen village. Prayers that will result in health loss if not answered are:

- Prayer for rain, this requires the player to make a spiral motion with their Oculus controller over top of the village to spawn a rain cloud;

- Prayer for protection, this will require the player to move their Oculus controller to their left hip and pull in the trigger to pull a champion from their champion bag, then the player will need to drop the champion on top of the village;

- Prayer for healing, which requires the player to touch the village with their Oculus controller.

Prayers that will lead to the village becoming heathens if not answered are:

- Prayer for a blessed festival;

- Prayer for absolution;

- Prayer for good fortune, which requires the player to reach into the bag of gold on their right hip and make a scattering motion with their oculus controller over the village

\section{Gameplay Writeup}


The player begins a new game - they are placed in the middle of the island with a village directly to the east, one to the north west, and one to the south. The are given a moment to orient themselves in the space before the eastern village starts praying, the player struggles to recognise the prayer, so they lean through the gamespace toward the eastern village, reach towards the village with their right Oculus controller and pull in the trigger to pick up the village elder. The player moves the hand with the elder to their ear and can hear the elder asking for rain. The player reaches back over to the village to put the elder back, then with that same hand, presses the grip buttons on the Oculus controller and makes a spiral motion. This spawns in a rain cloud above that village and answers that village's prayers.

While that was happening, the player heard a low rumble from the left side of the island, which they identify as an earthquake, they hurry over to the sound, noting that the southern village has started praying. Once near the potential earthquake, the player presses the grip buttons on both Oculus controllers, raises both above their head, and brings them down rapidly, releasing the grip buttons once completed. This results in a booming sound, and the prevention of the earthquake. The player is now aware that the southern villagers are praying. They move over to the southern village and identify the prayer as the prayer for protection. The player reaches to their right hip with their right Oculus controller, and pulls in the trigger to pick up a champion from their champion bag. The player then moves his/her hand over top of the village and releases the trigger to drop the champion into it. The player hears the village rejoice to indicate that the correct action was taken. 


\section{User Interface}

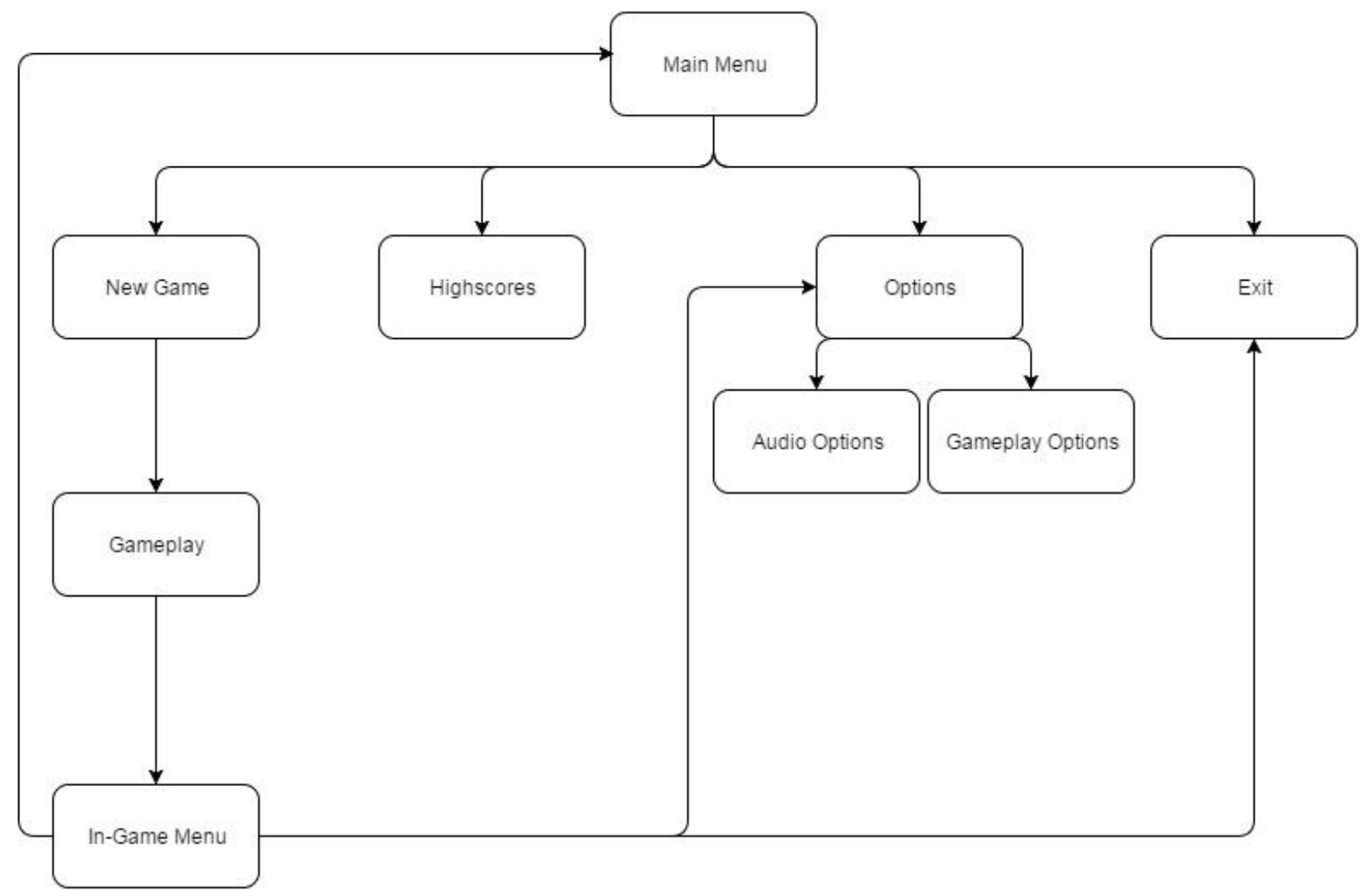

(Figure 5.1) User interface diagram

\section{Functional Requirements}

Main Menu: Presents an audio readout of each menu item when selected, simple cycle through. Ambient yet compelling music that conveys the tone of the game.

New Game/Introduction: Plays a short introductory audio clip, setting up the world and premise of the game, then moves into gameplay.

Highscores: Presents the top 5 scores recorded.

Audio/Gameplay Options: Opens a menu screen where the player can edit the the options of the game. Volume, control sensitivity, etc.

Exit: This will exit to desktop

Gameplay: This is where the game takes place 


\section{Risks/Challenges}

- Oculus cable: With the sheer amount of movement that this game requires, and the fact that it requires speed, this may cause the player to trip or become entangled with the Oculus cable

- Communicating Information: There are several pieces of information that the player may need that will be difficult to convey. The most obvious examples are the health of each village and how many villages have been destroyed. 


\section{Chapter 6}

Design Process Documentation 
"A designer knows he has achieved perfection not when there is nothing left to add, but when there is nothing left to take away"

Antoine de Saint-Exupery 
With the game concept selected and design documentation in place, the game build process could begin. I discarded the rapid prototype and began development of a new MINIKIN prototype.

As stated above, the operational prototyping technique was used for the creation of this game. The first stage of this process is to create a baseline prototype; a prototype containing the bare minimum features and mechanics. The first feature to implement into this baseline is Oculus Rift and Oculus Touch support. As I am working within Unity, this is a very simple process. I am able to simply use the OVR library for implementing Oculus head and hand tracking. The other piece of core framework for this baseline is a solution for three dimensional positional audio. Again this is a simple solution as Oculus released an audio SDK (Software Development Kit) that allows for extremely effective positional audio in a VR environment.

After having assembled the scaffolding of this prototype I can begin to implement some of the base game mechanics. To assess how this should occur, I can use the game design concept of minimum viable product. Minimum viable product, as a game design concept, is a version of a game that has had as many mechanics and systems stripped from it as possible, while still remaining a playable game. First of all I needed to fully understand what a minimum viable product would be for this game. The most obvious mechanic to strip back is the village prayers. My design document specifies six separate prayers that the villages can do. I can strip this back to one prayer requiring only one solution. I also reduced the number of villages. The gestural input is another mechanic that could be trimmed for the minimum viable product, replaced with a far more simple interaction method, such as simply touching the village. So to recap the current minimum viable product, there will be a reduced number of villages, each of which has only one prayer and that prayer is solved by touching that village.

This minimum viable product is now the baseline prototype upon which I can begin the process of throwaway prototyping. 
The first feature to implement into the initial game build was the gestural inputs that allow player input via the Oculus hand controllers. I initially intended to design a gestural input system myself from the ground up. This would involve having predetermined gestures that would be stored in the form of groups/arrays of coordinates that would create a sort of connect-the-dots version of the gesture. The player's movements would then be recorded and compared to the library of pre existing gestures. After a brief attempt at implementing this, it became clear that it would be far too time consuming and opted instead to use a prebuilt gestural input system from the unity asset store instead. I selected VR Infinite Gesture (Edwon Studio, 2016) as it is an extremely robust gestural input solution designed specifically for VR. VR Infinite Gesture allowed me to very quickly and easily implement any and all gestures that were needed. These included: 
Figure 6.1 - Making A Raincloud
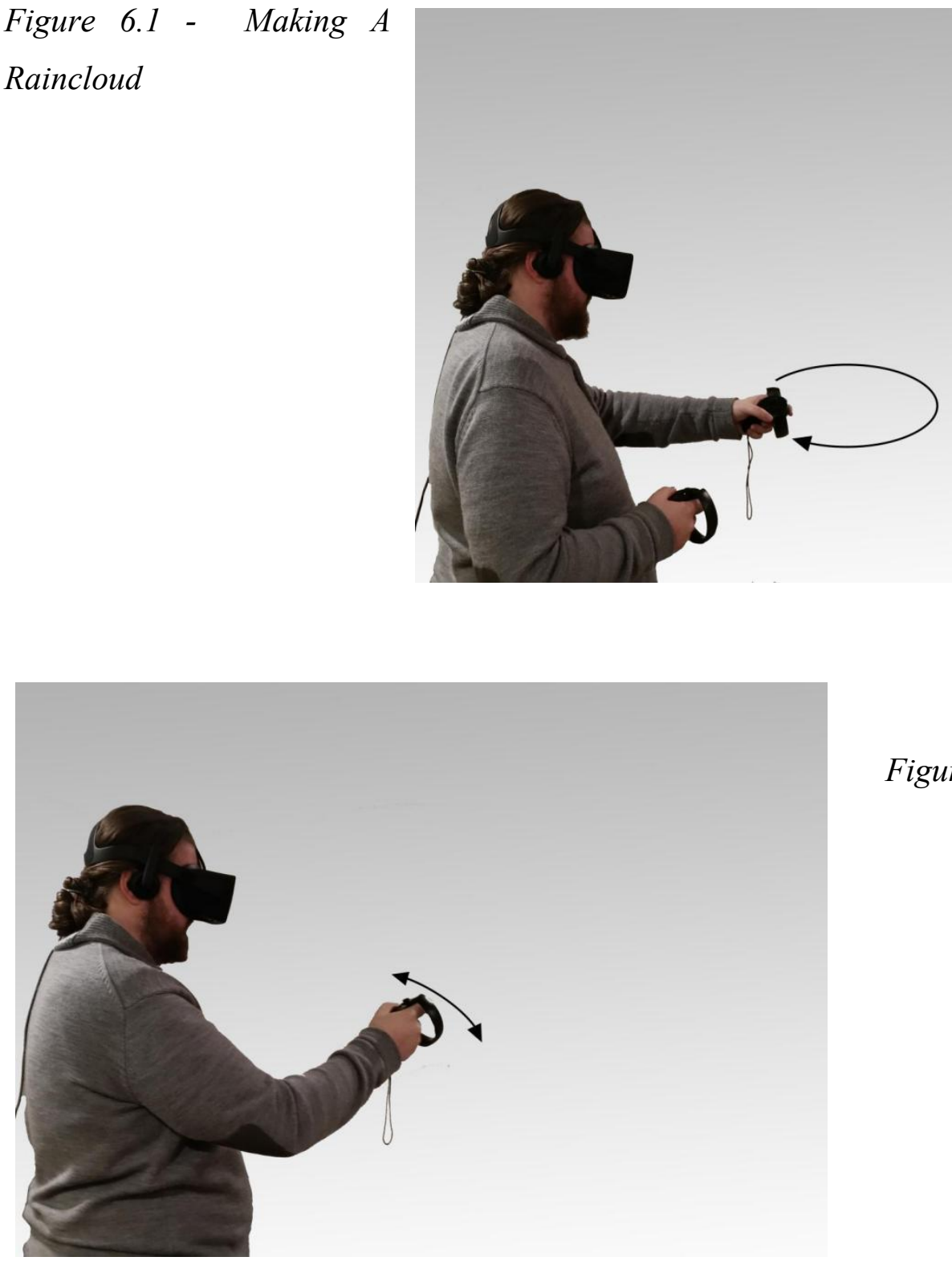

Figure 6.2 - Dispersing rain cloud

Figure 6.3 - Grabbing champion from bag

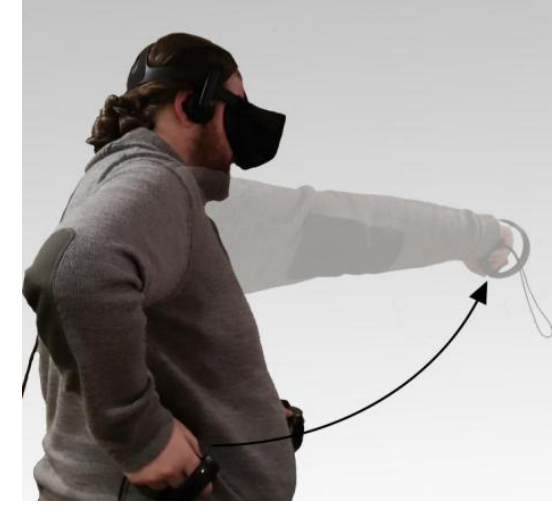


With the gestural input solution in place, the next step was implementing the dynamics of play, firstly with the village prayers and environmental issues. After implementing the village prayers it became clear that the gameplay was at once too shallow and too complex. That is there were series of tasks that were very simple; however, the amount of tasks present caused them to become overwhelming.

The remedy to this was to take the village system back to the drawing board and redesign it. The first major change was to remove half of the village prayers. It was decided to remove the heathenous village aspect of the game and all the associated prayers as it seemed at odds with the lighthearted tone of the rest of the game. That left just three prayers: water, protection, and healing.

At this point it was evident that leaving the village system so stripped back had the potential to create tedious play, as the gameplay is then a loop of "issue-solution-issue-solution" ad infinitum. The issue of being too simplistic resided not in the range of villager "problems", but rather in the mechanics of the solutions designed to resolve each problem. All of the solutions

were too similar and they were very simple to use and had no consequences associated with them if not executed correctly. To make these tools more challenging and fun, it was decided to make them more complex and varied in their uses (See gameplay flowchart 6.4 through 6.8). A large part of deepening these mechanics was to add consequences for incorrect or careless use of the player's tools. The end point of this design solution is that there are less situations for the player to remember; however, each situation is deeper and requires more thought. 


\section{General Gameplay}

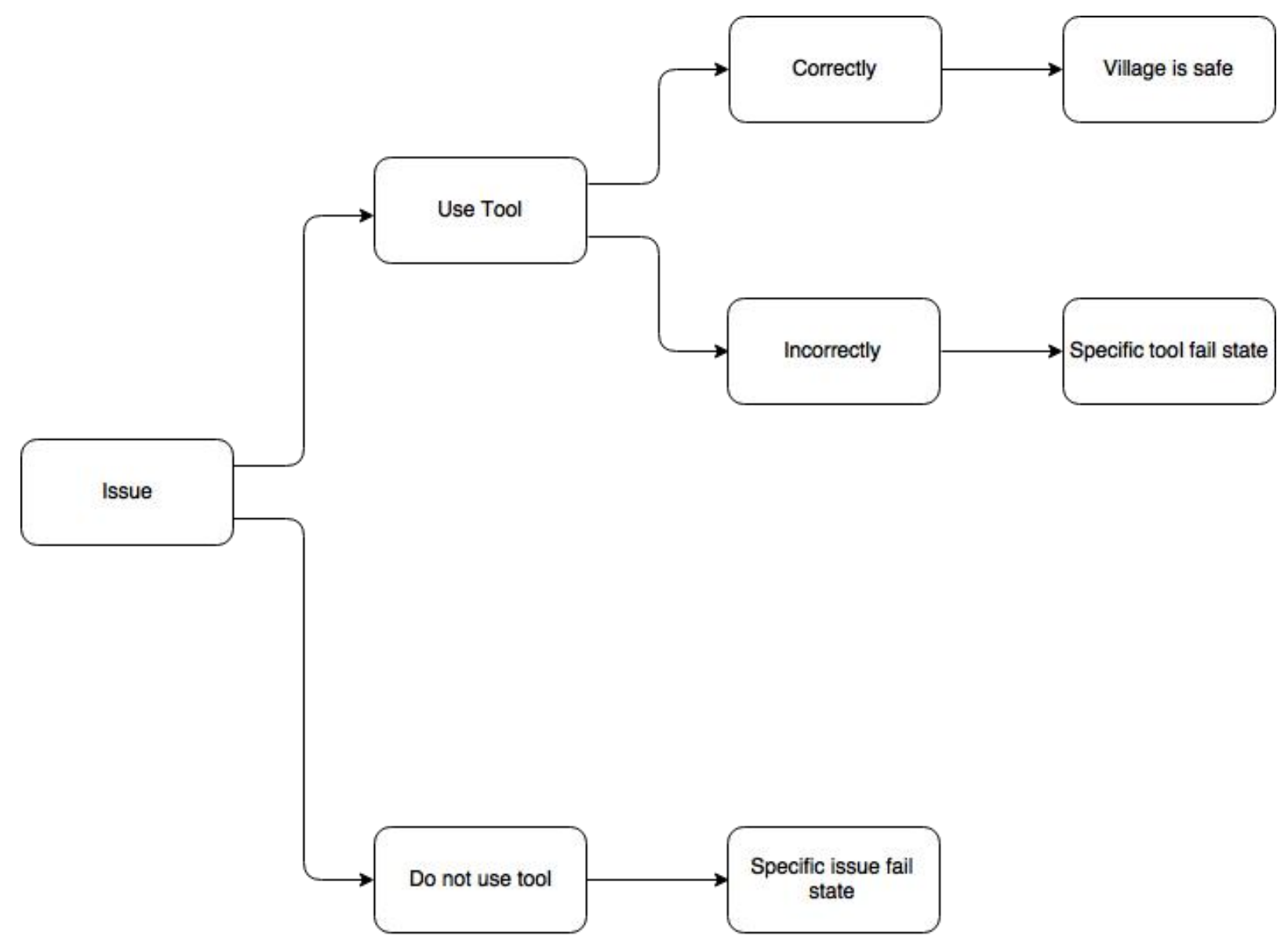

Figure 6.4 Gameplay Flowchart - General 


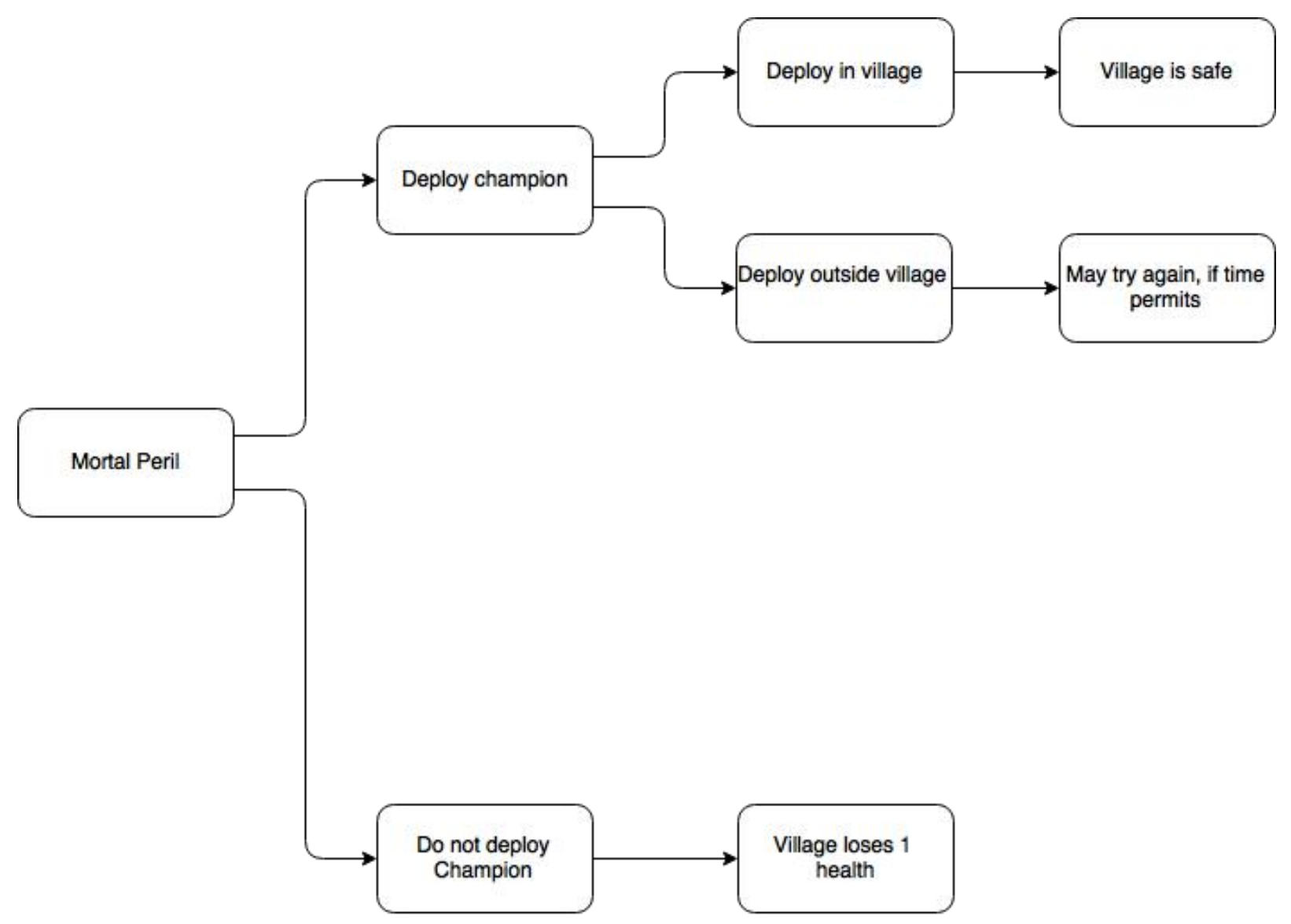

Figure 6.5 Gameplay Flowchart - Mortal Peril 


\section{Drought}

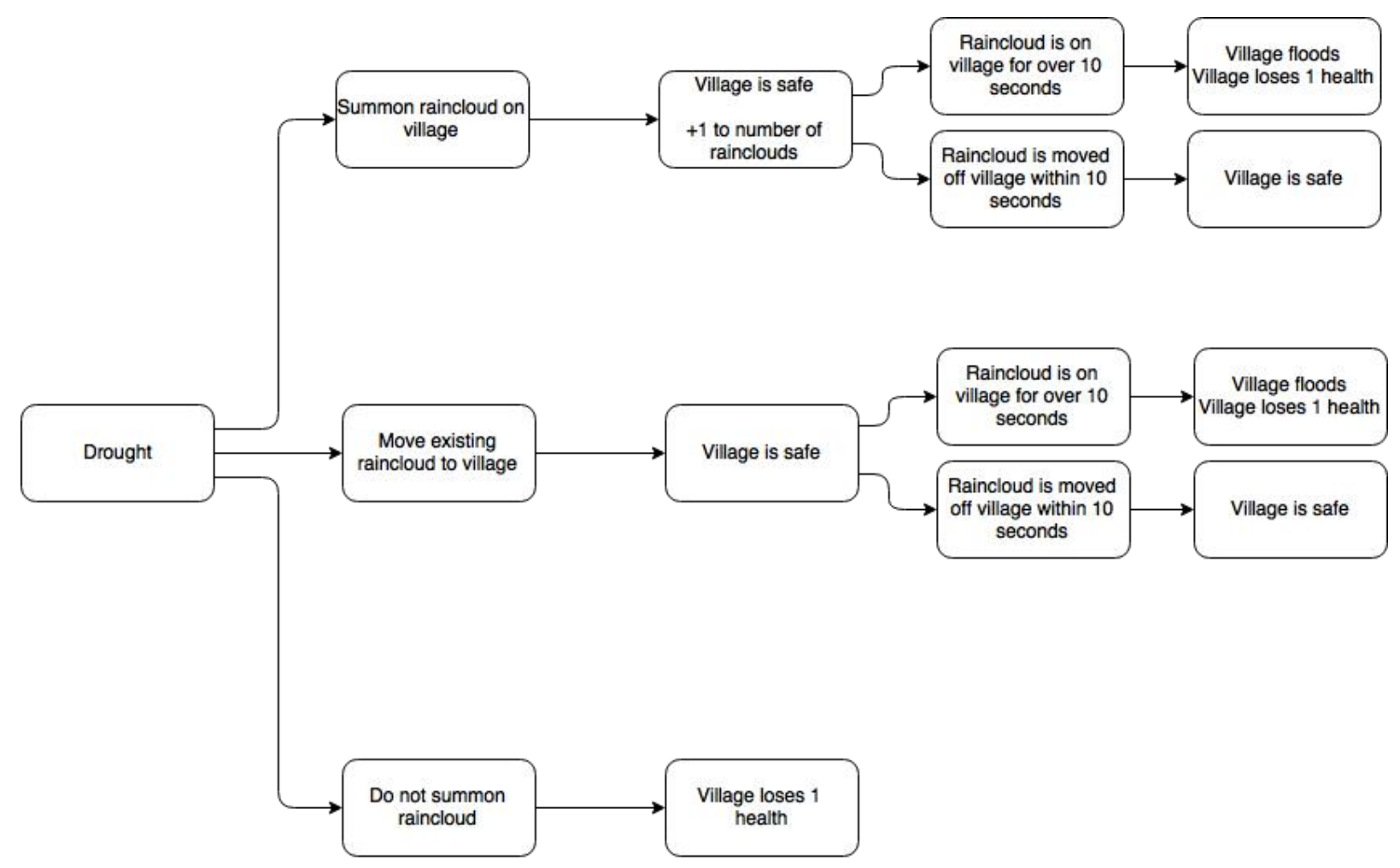

Figure 6.6 Gameplay Flowchart - Drought 


\section{Volcano}

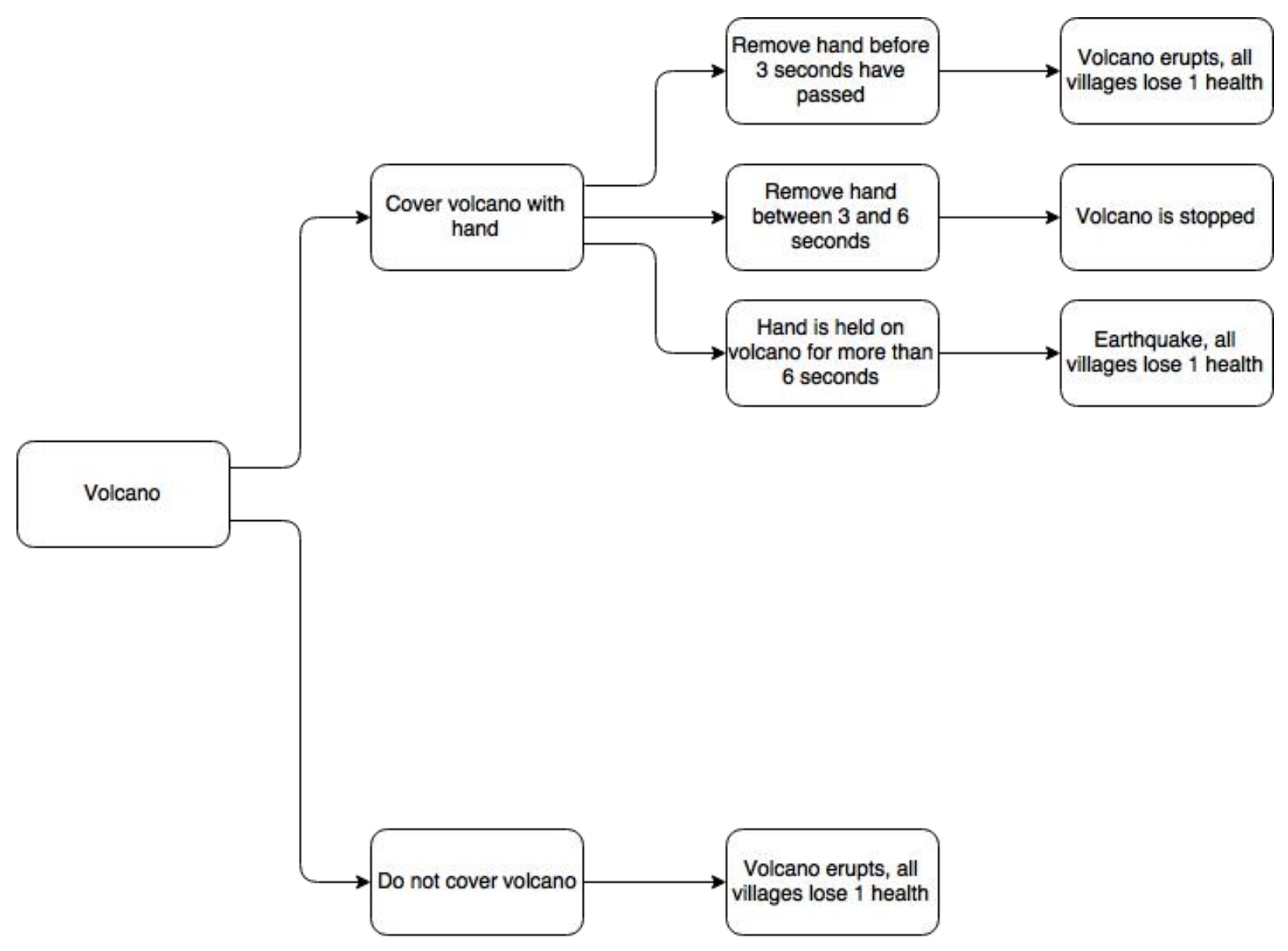

Figure 6.7 Gameplay Flowchart - Volcano

Sickness 


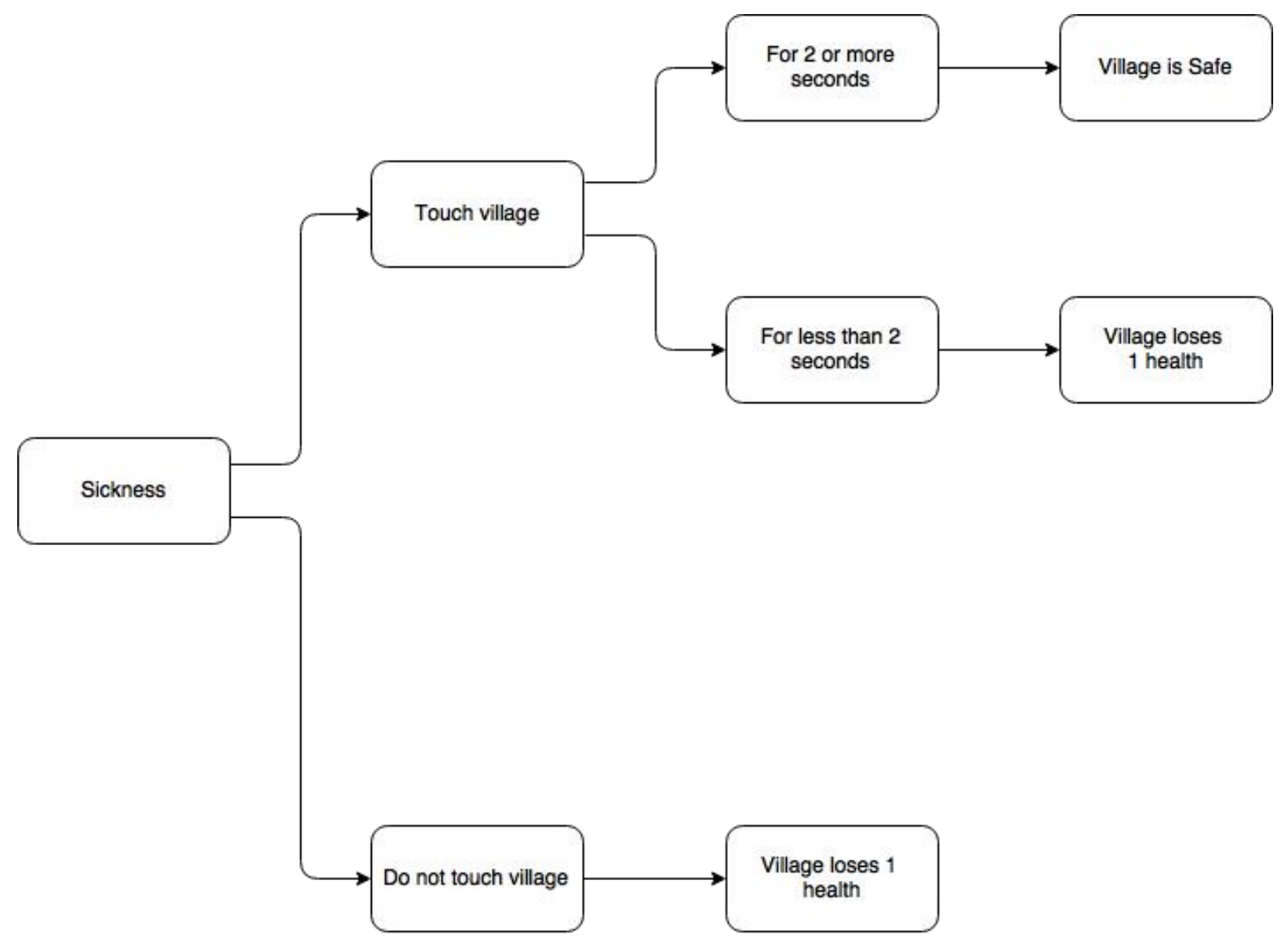

Figure 6.8 Gameplay Flowchart - Sickness

\section{Prototype Testing}


It had been planned to undertake user testing of a "minimum viable product" with blind players early in the development stages. However, as the subjects were both young and disabled, it required three separate ethics bodies be contacted for ethics approvals. All ethics approvals are detailed in the playtesting section below. As a consequence of these ethical requirements there were significant delays.

Due to these delays, all of the early prototype testing of the game was conducted with sighted testers. This obviously did not provide good insight into how visually impaired people would play the game, but significant work was able to be undertaken in developing the audio-only user interface that was able to convey all information required to play the game, as well as gestural inputs that enabled the player to put inputs back into the game.

One vital piece of information to come from this internal testing was that the game was very difficult to learn how to play. This was primarily due to the lack of visual queues able to be given to the player. Even after simplifying and reducing, the full set of mechanics as outlined in the design documentation were still too numerous and relatively complex so that sighted players, even those experienced in playing computer games, found the game difficult to play.

\section{Tutorial}

The most obvious solution to this issue was to add a comprehensive tutorial system to the game and the only way to convey significant tutorial information to the player non visually is through voice. Voice tutorial offers two choices, diegetic or nondiegetic. I chose diegetic narration as it offered an opportunity to inject more character and narrative into the experience. This forced me to develop the specifics of the character and theme of the game.

At this stage in the development the specifics of the game's setting and identity had been left up to the player's interpretation, with the only established plot points being that there was an island of some kind and that you were designated to look after it. My initial consideration was to make the island tropical and set the game somewhere in the Caribbean. However, it was 
considered that a more interesting aesthetic may be achieved by twisting the expectations of the player and set the game somewhere vastly different. I explored a number of possible locations for the island, with north of England and Scotland being the area I finally selected. This location was not where one would expect this style of game to take place, plus this setting allowed for more interesting options in terms of accents for the narration.

The next task was to develop the tutorial, with the basic structure having a narrator introduce the game and setting, then talking the player through the gameplay and how to assist the villagers resolve their problem. Once the player has completed each task, another village prayer would occur and be explained. This was repeated until all mechanics in the game had been explained. 


\section{Chapter 7}

User Testing 
"A design isn't finished until someone is using it" Brenda Laurel 
The first step in the playtesting process was to define who to test with. The most important aspect was that they must be visually impaired (all testers were blind). I also needed them to be above the age of 16 as this simplified the ethics processes. As stated above, I worked with the Blind Education Network New Zealand (BLENNZ) in Wellington to find local visually impaired people to test with. BLENNZ is the network for resource teachers working with blind people throughout New Zealand.

Contact was made with teachers from BLENNZ in July 2016 and discussions began regarding broad game concepts and the possibility of accessing playtesters through the BLENNZ network. These initial discussions with the BLENNZ network staff indicated that many visually impaired young people locally have very limited access to computer games and a number will have never played them. It was also thought that the playtesters would never have used an Oculus Rift or other type of virtual reality head mounted display.

\subsection{Ethics Approval to Work with Visually Impaired Playtesters}

\section{Health and Disability Ethics Committee}

An informal submission of a Scope of Review form was made to the Health and Disability Ethics Committee in July 2016. This submission outlined the overall design project and the need to work with blind playtesters. Their response was that as this project sat outside of health and as such I did not need ethics approval from the Health and Disability Ethics Committee to proceed with playtesting the game (see letter 4 Aug 2016 appendix 2.5). 


\section{Victoria University Human Ethics Committee}

All research involving human subjects requires approval from the Victoria University Human Ethics Committee. In November 2016 a full submission was made to this committee outlining the scope of the research:

- That participants must be 16 years of age or over

- That a member of the BLENNZ network would be in attendance during playtesting

- That playtesting take place in the school environment (some playtesters were adults so testing was done in a place of their choosing)

- Associated forms and documents:

$\circ \quad$ Information sheet (see appendix 2.2)

○ Consent form (see appendix 2.1)

$\circ \quad$ Pre- and post- playing questionnaires ( see appendix 2.3 and 2.4)

While this age restriction assisted with making the consent process less complicated, it also restricted the group of blind users that were able to be involved in the project. Both the BLENNZ teachers and the playtesters (all over 16 years of age) voiced disappointment that a large number of younger learners not were able to experience the game.

Approval from the Victoria University Human Ethics Committee was obtained in February 2017 (see appendix 2.6).

\section{BLENNZ Ethics Approval}

All prior ethics approval information and documents were sent to the Blind Learning Education Network New Zealand office in Auckland in March 2017. Along with these, a specific BLENNZ ethics approval form was completed. Approval was gained in May 2017 from the BLENNZ Ethics Committee (see appendix 2.7) 


\subsection{Playtesting}

Playtesting involved a short interview before the test; the test itself, which was observed by the researcher; and a post-test interview. The interviews were voice recorded but no other recording of the playtests or interviews were made, apart from some still photography taken to be used in this document. Separate consent was obtained from the testers for this. Information sheets and consent forms (see appendix II), along with audio files of each were provided to prospective participants prior to them agreeing to take part. The pre- and post-test interview questions are also contained in appendix 2.3 and 2.4

The goals of the play test were:

- To assess the effectiveness of the game; whether the testers were able to achieve the objectives that the game sets forth, which I have labelled Playability.

- To determine if the game would be compelling and fun for the participants; the game's Enjoyability.

- What specific feedback and insights could blind users give to further enhance the game to understand How the Game Could be Improved.

Playtesting occurred late in the development stages of the game and meant that participants were not testing an early prototype, but rather the near to complete game. This late playtesting provided a more complete experience of the game for the playtesters and allowed a more confident determination to be made on the feedback regarding the aspects being tested.

Playtesting occurred over a two-week period in late May/early June. The delayed start to playtesting meant that I had a limited number of playtesters (four). However, this smaller of testers allowed for more in depth testing to occur. 


\section{Playability and Enjoyability}

Throughout this thesis, the subject of playability has been discussed in several contexts and defined in several different ways. Initially playability was discussed in the literature review, where several different, yet similar, definitions were put forward. These all defined playability as a measure of the overall quality of a game. Playability was then briefly discussed in the design criteria. In this section it was used in its broadest sense, as a qualifier for whether the game might conceivably be played by a blind user, irrespective of 'fun' or entertainment.

There is currently no literature relating specifically to blind playability, so this has required some consideration within the context of this thesis to gain insight into how blind playability might be defined .

\section{Defining Playability}

The definitions of playability put forth in the literature review all place significant emphasis on the entertainment value of a game. While there is some merit in considering the entertainment value of a game, it seems more useful to consider playability as something distinct from entertainment value, relating instead to the ease with which a user can interact with and understand the game and it's systems. This allows a designer to have a far more focused view on both the entertainment value and functionality of any given project. The focus of this design project has been to design a computer game that was able to be played by a user group who currently find the vast majority of computer games unplayable. This then provided a unique opportunity to consider playability in its most distilled form.

Due to no visual feedback being relayed to the player, the amount of information that can be delivered to the player is greatly reduced. This diminished interface removes the main source of feedback to the player, severely limiting my ability as the designer to convey game crucial information. So to succeed in this project it was necessary to clearly identify those components of the game that are absolutely necessary to enable playability. My view as it relates to this project, and more broadly, is that the playability of a game can be broken down into three core elements:

\section{The Information Exchange}

The information exchange is how the game system allows the player to provide information into the game and how well the game provides information back. 


\section{The Difficulty of Mechanics}

How difficult it is for the player to complete the tasks that the game sets forth.

\section{The Quality of Tutorialisation}

The quality of tutorialisation is how successfully the game teaches the player to play. It is important to note that this is not just limited to direct tutorials. A game that contains no tutorial could still have excellent quality of tutorialisation if the game mechanics themselves are so intuitive that the player can naturally learn them.

By this definition playability is a distinct aspect of the game that does not relate to how entertaining it may be; a game can be playable without being entertaining. So for the purposes of this thesis I am proposing that a game's overall quality is considered using two discrete factors: Playability and Enjoyability.

\section{Defining Enjoyability}

To define enjoyability I will be using Raph Koster's theory of the types of 'fun' (2005). Koster defines these as:

- Mastering a problem mentally

- Aesthetic appreciation

- Visceral reactions

- Social status signals

Mastering a problem mentally is immensely enjoyable; when the player is given a problem to solve and a set of tools to do so, fun is the process of the player learning the specifics of how the tools can be used to solve the problem and the optimal methods of doing so. 
Aesthetic appreciation is the enjoyment of any aesthetics the game contains. This could mean the visual style or audio; even narrative and plot are contained within aesthetic appreciation.

Visceral reaction is most closely related to Csikszentmihalyi's (1990) idea of flow. This is what comes about at the end of fun, once the player has mastered the mechanics of the game and the player's ability is precisely met by the challenges of the game.

Social status signals are anything within a game that give the player an indication of being at a higher social standing. These are most often present in multiplayer or competitive games.

Unlike playability, a game can be enjoyable when meeting just a small number of these criteria. However, the more of these criteria that are met, the more enjoyable the game is likely to be. The main way in which playability and enjoyability differ is that while playability is highly dependant on each of its constituent parts, a game can excel in enjoyability with just a few or even a single criteria being met.

\section{Assessing Playability}

Playability was assessed at playtesting through both observation and the post-test interview. The aspects of playability are all interrelated to some degree.

Observation of the tester was the primary method for testing the efficacy of the information exchange. The fact that the users were able to play the game and complete the tasks set forward throughout the game speaks to the quality of the information exchange.

Determining the difficulty of the mechanics was done through observation as above and the post-test questionnaire where the tester was asked "was the game difficulty optimal, too easy, or too difficult?". The majority of testers answered "optimal" to this, with only one tester answering that the game difficulty was "maybe a little easy". This indicates that the difficulty of the mechanics was pitched at approximately the right level.

The quality of tutorialisation was assessed through observation of the testers playing the game. If the testers were able to progress through the game without assistance, this would indicate that the tutorialisation is sufficient to complete all game tasks. For most of the testers, they were able to 
progress through almost all of the game without issue. The areas in which they required assistance remained quite consistent throughout the playtests, with the main issue revolving around attempting to disperse the rainclouds. The testers would be told by the tutorial character to grab the cloud and shake their hand back and forth. The issue was that it was not specified how fast they needed to shake their hand and as such they would shake their hand far too slowly.

There was also a specific question in the post-test questionnaire that helped in assessing the quality of tutorialisation, "Could you play this game again without having the rules explained again?". This question provided mixed answers, most of them being positive, ranging from "yes, I could" to "I think so... if there were an option where you could repeat them if you got confused" and "maybe, [if I could hear the instructions] one more time". One play tester when asked which part of the game they liked the best responded "The tutorial was great... it really didn't feel like a tutorial"

\section{Assessing Enjoyability}

Problem mastery was an aspect of enjoyability that I was aiming to achieve with this project, so was specifically assessed during playtesting. Several of the playtesters, when asked what their favourite part of the game was, responded that their favourite part was the feeling of getting better and improving at the game. "Near the end, getting used to, kinda, the movements you needed to do to complete an activity... getting better" And "Succeeding... the feeling of 'oh good, I did it right". This shows that for the testers the experience of learning and mastery, and the feeling of 'fun' that comes alongside that, were very much present in the game.

Aesthetic appreciation was important in the design of this game. Testing showed that the endeavour of creating aesthetic appreciation in the game was largely successful, but is an area of further design development that could take place in the future. When asked their favourite part 
of the game, one tester replied, "I really enjoyed the sound effects, and the voice acting... The atmosphere was really well set". Some testers suggested improvements for the game could be more ambient sounds, more characters, and potentially some kind of music. The players enjoyment in the game was also observed with gestures and movements, with one player having sustained giggling throughout the playtest.

Visceral reactions and social status signals were not aspects of enjoyability that this game aimed to express.

Overall the playtesting showed that the game design achieved the goals; it was both playable and enjoyable for the testers. All those who played expressed a desire to play the game again and several conversations took place about how to make the game available to others in the blind community locally.

While the playtesters had a number of ideas about how the game could be improved (outlined below), but the overall playtesting could be summed up with the following comments from the testers:

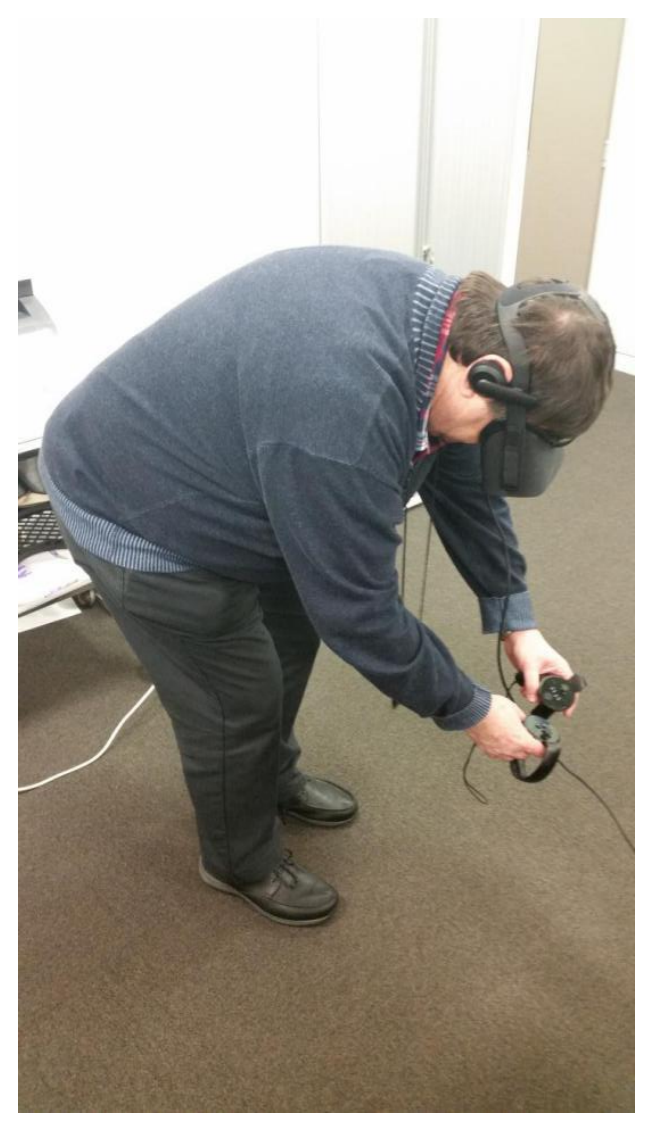

"It was the best game experience I've had"

Would you play this game again? - "Yes, because I could [actually] do it"

What was your favourite part of the game? - "All of it, actually. Being able to complete the tasks, the descriptions [of the environment]" 


\section{How Could the Game be Improved}

Several of technical issues were raised during the playtests and these were rectified as they became evident during the playtest period. Examples of these are:

- The tentative way that the players used the hand controllers (likely because they had had limited experience with this type of technology) meant that thresholds had to be increased in order to register.

- Confusion regarding the height that certain objects were residing at. Again, thresholds were altered, and some sounds re-recorded to more clearly illustrate where objects resided

- Speech being too quiet when compared to other sounds in the game.

- More narrative throughout the game.

- More description of the game environment (the Island).

- Improving access to the game was discussed at length by both participants and teachers. Concern for how those under 16 years of age may get to participate in the game locally (an agreement has been made with BLENNZ to take the game and gaming equipment to an open day at the local BLENNZ school at the completion of the research project when consent is no longer required). BLENNZ have also invited me to showcase the game at a technology expo in Auckland in December 2017.

- Both teachers and playtest participants also stressed that improving access to blind games through using iPhones would be a very important next step.

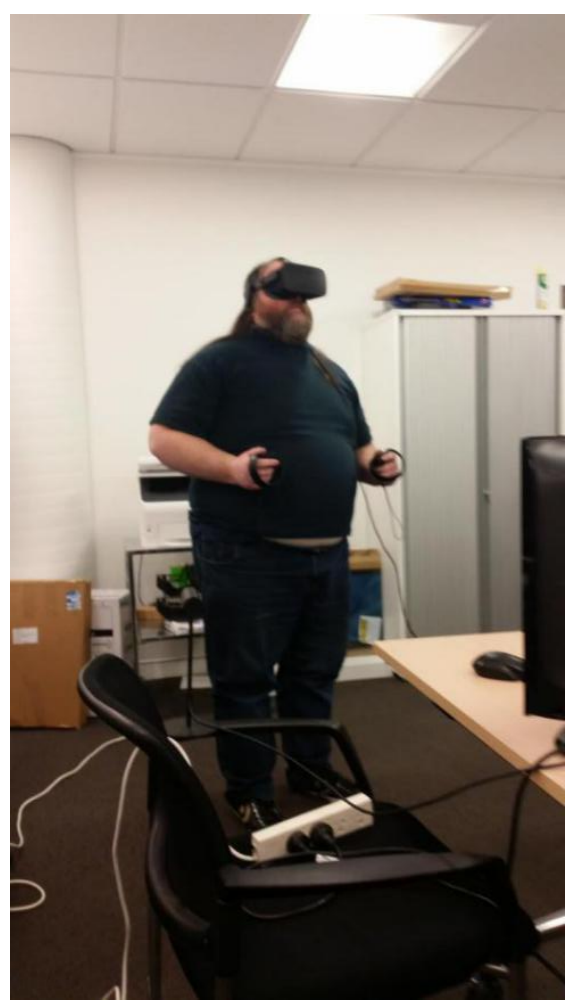




\section{Chapter 8}

Conclusion 
"It's a terrible thing to see and have no vision"

Helen Keller 
Whether we like it or not, computer games are a large and growing part of our culture globally. They provide entertainment, education and the opportunity for social interaction. Current games are largely designed for an audience that has "perfect cognition, sensory and physical development" (Cheiran, Nedel, Pimenta 2011). The question that now needs to be asked is how do we now improve accessibility for those currently excluded from modern, mainstream computer games. Because the primary interface of mainstream computer games is visual, access to these games is, generally, extremely limited for the blind community.

Designing a computer game for blind users presents significant design challenges, specifically designing processes that allow information exchange between the player and game. However, as more non-visual games are designed and developed, more conventions of non-visual game design will be uncovered and understood, allowing non visual games to further develop.

As evidenced by the playtesting, the project designed for this thesis, MINIKIN, met the criteria of both playability and enjoyability with the blind playtesters. Observations and questionnaires administered during playtesting showed that all players were able to play the game, with the playtesters stating that they enjoyed the aesthetics and mechanics within the game. All players said they wished to play the game again.

As with any design project there is still opportunity to further improve the game. The original design document had numerous elements that were not included in this prototype, such as characters (ie the village elders) and mechanics (ie volcanoes, earthquakes), that could now be reintroduced into the gameplay using level development and further tutorialisation to enable the player to manage the more complex gameplay.

Playtesting also highlighted several additions and enhancements that could be made to the game. Improvements that were suggested during playtesting, such as developing fleshed out lore or a compelling narrative, and providing richer descriptive aspects, could readily be implemented. There is also potential to develop the game further using other platforms. One option could be to explore multiplayer platforms; one play-tester in response to suggestions for improvements to the game, asked if it could be developed so that he would be able play it together with his 
grandchildren. It may be possible to develop an asymmetrical format where the main player (not sighted) could be using the Oculus HMD and other players (sighted) may be playing as characters within the village using other platforms.

Virtual reality offers many positive aspects for non-visual game design. Aside from the obvious aspects that are intrinsic to virtual reality, it also offers new and interesting implications for teaching physicality and spatial awareness for visually impaired users, and as Seki and Sato (2011) outlined, it is excellent for teaching orientation and mobility skills. However, there is an issue currently with developing non-visual content for VR, and that is that it is currently not freely available within the blind community. Both the Oculus Rift and HTC Vive are prohibitively expensive and somewhat difficult to obtain at this stage. This is, however, a short lived problem, as VR HMDs are becoming more affordable and available, it may not be long before VR HMDs are a household item.

An important next step is to develop a non-visual game on a platform that is more immediately and widely accessible to blind users. The iPhone is used almost exclusively within the blind community due to the numerous accessibility features it offers. It is likely that any development forward with the design concepts developed in this thesis would have the iPhone as the platform.

The importance of video games and how they sit within the context of our culture was strongly highlighted during this project. It is very easy to dismiss computer games as purely entertainment or a time-wasting pastime, but the discussions with the blind playtesters showed that one of the most important aspects of gaining access to computer games was the social aspects that games provide.

Being able to play the games with friends and family (both blind and sighted) and, perhaps more importantly, being able to talk about the experiences within the game with others who have also played it, was identified as something playtesters were eager to do. 
It is clear that the blind community has been largely excluded from participating in computer gaming. All participants had attempted to play computer games in the past, some using sighted friends to give commentary and instruction, attempting to guide them through the visual game space, and others trying current non-visual games.

Both the playtest participants and the BLENNZ teachers involved in the playtesting expressed a desire to make MINIKIN available to others in the blind community, especially those under sixteen who were not eligible for the playtesting. I will be continuing to work with BLENNZ and the Blind Foundation to make this game and hopefully other similar games more available to blind players.

My primary goal throughout this thesis was to discover the implications of designing a non-visual game for VR. First and foremost, it presented an immense challenge to the design process, largely due to the need to 'unlearn' a lot of existing game design conventions. This has granted me a number of insights into non-visual games, many of which were purely technical, relating to concepts such as sound design, interaction design, or tutorialisation.

But the most valuable insights I gained were the ones I found through working with the visually impaired. This group helped me to realise just how much I, and many others, take computer games for granted. For many sighted people computer games have become integrated into their daily lives, from playing games on a phone, to watching eSports. Games themselves give us fun, education, escapism; they can keep us occupied while waiting for the bus, or they can bring communities together, online or in person. This leads to what was perhaps my most surprising and indelible insight from this project. Talking in depth to a group of people who lack access to games brought to light that it is not necessarily the 'fun' of the game itself that is missed the most, it is the social connections that games can forge, from a grandfather playing with his grandchildren, to friends discussing a computer game at school. It is up to designers such as ourselves to advocate for, and participate in the creation of more accessible games in order to enable everybody to participate in the social and enjoyable pastime that games can be. 


\section{Appendix I}

Appendix 1.1 - Terraform Design Document

\section{Terraform: Design Document}

\section{Game Description:}

Terraform is a non-visual game for the HTC Vive and Oculus Rift. The player plays as a robot sent to terraform a hostile planet for inbound human inhabitants.

\section{Functional Specifications}

\section{Core Game Play}

The playable character (PC) moves, first person, in a large 3D space, consisting largely of open plains. The PC is tasked with constructing buildings, gathering resources, and introducing wildlife to the game world. The player will be in contact with the mothership, which will provide instructions and useful hints, functioning as the tutorialisation of the game mechanics.

The player starts with a basic set of tools: A mineral scanner, used to locate mineral deposits; a GPS tracker, used to locate man-made structures; a mineral extractor, used to harvest minerals from a mineral deposit; a solar array, for supplying power to the colony; and a fabricator, used to turn raw materials into useful items. It is then the players job to assemble these basic tools and harvest resources, then use those resources to build more complex tools

The player will begin on a basic planet and be given a fairly simple set of instructions. The first planet's requirements for habitability will be fairly low, serving to introduce 
many of the base mechanics. Upon completion of terraforming the first planet, the player will move to another, more complex planet. The average play time should be between 45 to 90 minutes.

\section{Game Flow}

Actions the PC can perform are:

1. Move freely through the space

2. Pick up object

3. Activate equipped object

4. Put object in inventory

5. Interact with object, i.e. the fabricator

6. Scan for objects in a certain area

\section{Characters}

Player character: Nameless robot sent to hostile planet to terraform it.

Mother AI: The AI aboard the mothership that communicates directly with the PC. Serves as tutorial, shopkeep, and plot.

\section{Game Play Elements}

There are several elements that the player will be required to pay attention to regularly:

- Currency: For interactions with the mothership, the player may require currency. The main currency is refined minerals, that is raw mineral harvested by extractors, then run through a refinery. Some rogue traders may ask for more exotic items as payment

- Supply Drops: Every 5 days (days advance when the player docks at the recharge station, see below) the mothership will send a shuttle to the planet's surface if the PC has filled out a requisition form and has the correct amount of refined materials. The shuttle will contain whatever supplies the player has requested.

- Battery life: The PC has a limited battery life, that must be recharged regularly at the solar array. If the battery is left to run out completely the mothership will dispatch a remote battery replacement device in place of the next supply drop. This will result in 
a hefty fine for the player as well as that supply drop being missed. The player will be alerted when the battery life reaches $20 \%, 10 \%$ and $5 \%$

- Hazards: Occasionally, some calamity will befall the PC's colonization attempt. These will range from ecological disasters such as solar storms to more exotic threats like giant sand worms

- Upgrades: The PC will be able to outfit themselves with new equipment, such as more accurate scanners or more efficient batteries.

- Habitability: This is how safe the current planet is for human inhabitants. It is on a scale from 0-100, 0 being instant death, 100 being complete earth-like atmosphere.

- Incoming Humans: There is a set amount of time before humans arrive on the planet. The planet must be at least habitable by this point. If the planet is not sufficiently habitable, the player will be forced to retry the stage. 


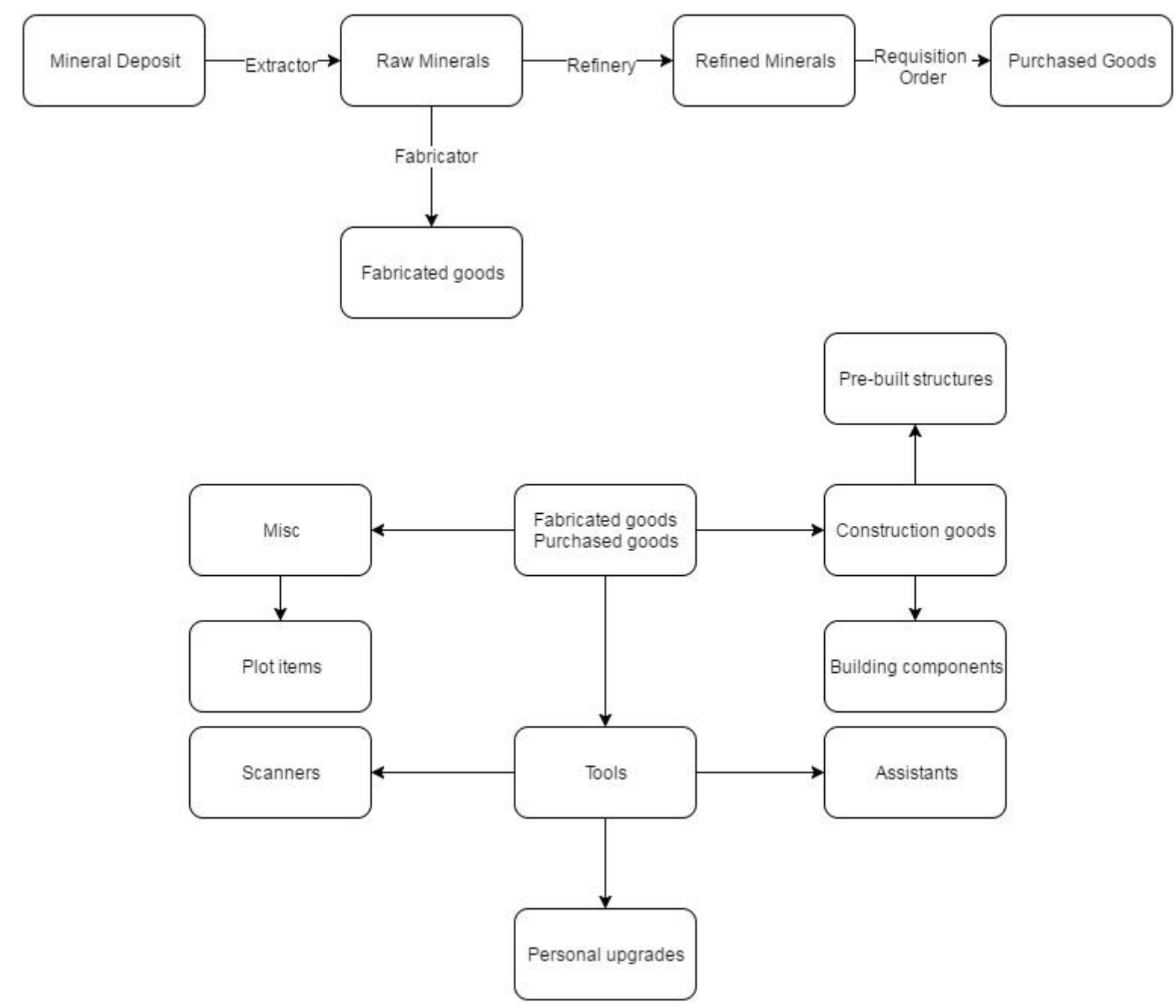

Figure 1 Materials Flowchart

\section{Mineral Processing}

Mineral Deposit: These are spots in the world where there are rich buildups of minerals Raw Minerals: When an extractor is placed on a mineral deposit, it will create Raw minerals Fabricated goods: Placing raw minerals into the fabricator will allow the player to fabricate items

Refined Minerals: A refinery will refine raw minerals into refined minerals, these are the currency with which you can purchase items 
Purchased Goods: Filing a requisition order with the mothership will allow the player to spend refined minerals to purchase goods.

\section{Purchased/Fabricated Goods}

\section{Construction Goods}

Pre-Built Structures: These are structures that require no construction, they are delivered to the player in one piece. These include mineral extractors and solar arrays

Building Components: These are the components required to construct larger structures. The primary building component is the construction site. A construction site defines the area in which a desired structure can be built.

\section{Tools}

Scanners: These are scanners that will allow the player to locate new objects in the game world. The player starts with a mineral scanner, and will be able to acquire scanners to locate more exotic materials.

Personal Upgrades: These are modules that will add new abilities to the player, or increase the effectiveness of the existing abilities.

Assistants: These are small, non-sentient AI's that will help to automate tasks. For example, an assistant could be used to automatically empty full mineral extractors and place the minerals into the fabricator.

\section{Misc}

Plot Items: These are items that have no gameplay implications, but will provide information on the game world and story thereof. 


\section{Gameplay Writeup}

Player is placed on planet surface with crate of supplies. Crate contains basic solar panels used to recharge players battery, 1-2 mineral extractors used to extract minerals from mineral deposits, and components to create a fabricator. Player is instructed to unpack crate contents, and is introduced to the gps tracker, when equipped this will create a distinctive object sound at the location of an object of the player's choosing.Player equips the gps tracker by making a cyclical motion on the left Vive controller's trackpad to cycle through the different scanners (Vive) or using the LB/RB buttons on their controller to cycle through the scanners (Oculus), and follows the object sound to the supply crate, using artificial locomotion, using the right hand Oculus controller's trackpad (Vive) or using the left joystick of their controller (Oculus) and open it, supplies are added to their inventory. Player is then given a list of tasks:

1. Set up solar panels

2. Locate mineral deposit

3. Set up mineral extractor

4. Assemble fabricator

5. Fabricate another mineral extractor using extracted minerals

Player accesses their inventory and equips the unassembled solar panels. Player uses solar panels, placing them on the ground, where they begin to assemble themselves. Player is introduced to their battery life.

The player is then introduced to the mineral scanner. When equipped the mineral scanner will create a distinctive object sound on all mineral deposits within $\sim 15 \mathrm{~m}$. The player is then instructed to locate a mineral deposit using the mineral scanner. The player equips the mineral scanner and locates the nearest mineral deposit, then moves over to it. The player then accesses their inventory to equip the unassembled mineral extractor and uses it on the mineral deposit they located. The mineral extractor will set itself up and inform the player that mineral will be ready for collection in 10 minutes.

The player equips the gps tracker and sets it to the supply crate, then moves back towards it. Once at the supply crate, the player picks up the fabricator and sets it near the solar panels, at which point the fabricator begins assembling itself. Once the fabricator is assembled, the player is instructed that the now empty supply crate can be fed into the fabricator and repurposed into a 
new mineral extractor. The player returns to the supply crate and collects it, then feeds it into the fabricator and begins the fabrication of a new mineral extractor.

\section{User Interface}

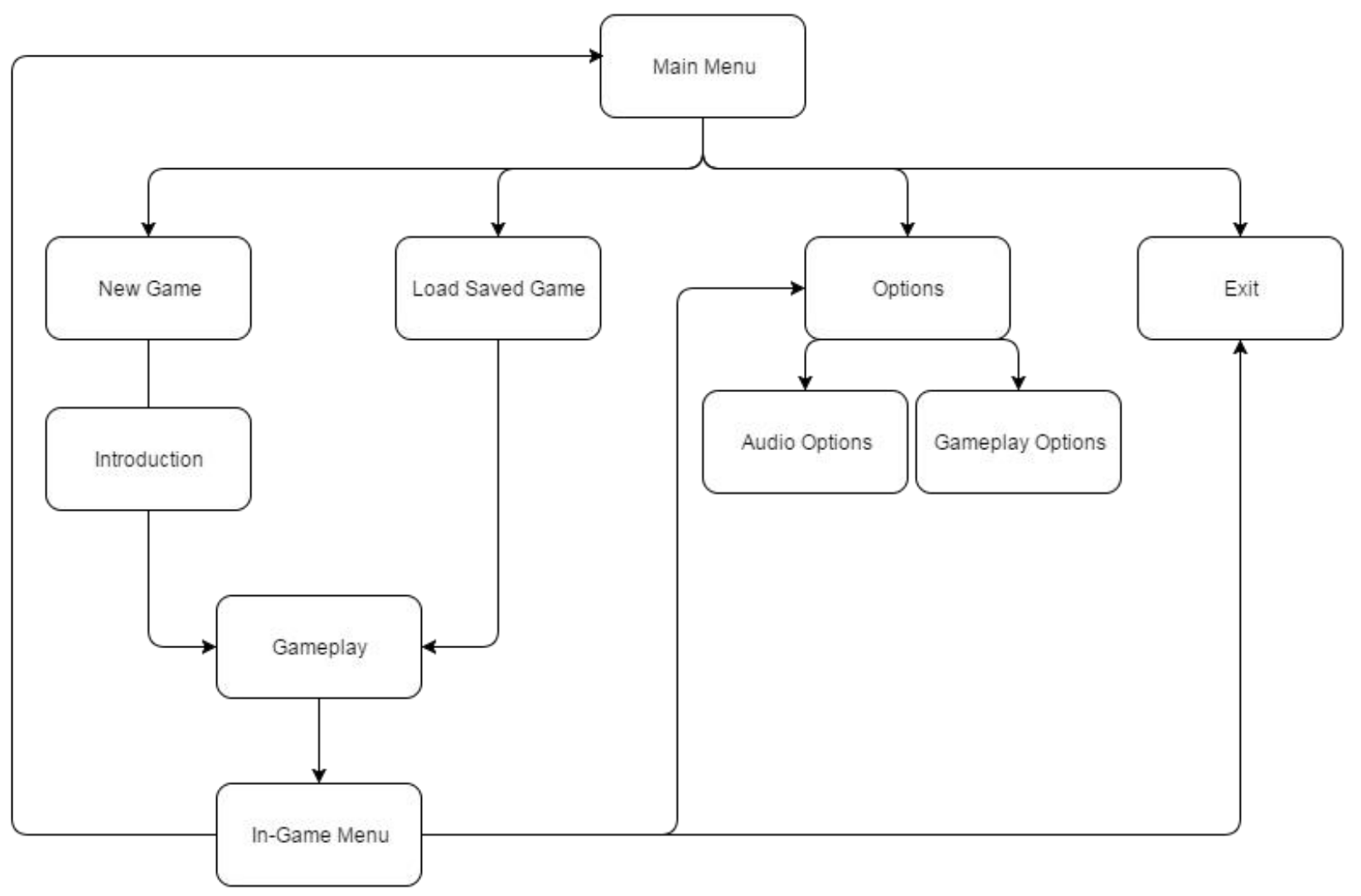

Figure 1 - User Interface Diagram 


\section{Functional Requirements}

Main Мепи: Presents an audio readout of each menu item when selected, simple cycle through. Ambient yet compelling music that conveys the tone of the game.

New Game/Introduction: Plays a short introductory audio clip, setting up the world and premise of the game, then moves into gameplay.

Load Saved Game: Allows the player to select and load a previously saved game.

Audio/Gameplay Options: Opens a menu screen where the player can edit the the options of the game. Volume, control sensitivity, etc.

Exit: This will exit to desktop

Gameplay: This is where the game takes place

\section{Risks/Challenges}

- Locomotion vs. player motion: When utilising the artificial locomotion to move through the game space, if the player is collides with an obstacle a distinctive collision sound will play to indicate the player cannot move further in that direction. However, if the player is to physically move themselves in that direction, they may end up clipping through the object. (Oculus Specific) 


\section{Private Eye: Design Document (developed March 2016)}

\section{Game Description}

Private Eye is a 50's noir styled adventure game based around a blind private investigator attempting to solve a case

\section{Functional Specifications}

Core Gameplay:

The core gameplay of Private Eye consists of exploring areas to find items and clues that may aid in the solving of puzzles, riddles, and other problems that may be impeding the player's progress through the game. Private Eye will take the form of a traditional adventure style game with significant emphasis of character and plot. In order to navigate spaces, the player is equipped with a white cane. This can be used to 'tap' the ground in front of the player, this will inform the player of what occupies the space in front of them.

While existing in the traditionally dark and gritty noir style, Private Eye will remain a relatively light and hammy tone, evoking that of 1940's radio dramas. The noir style was chosen as it allows for a great deal of diegetic, player character narration.

Game Flow:

Actions the player can perform are

1. Interact with/pick up objects in the environment

2. Use 'white cane' to detect objects

3. Examine an object.

4. Examine current inventory

Possible Characters:

- The Detective: This is the playable character. A down on his luck, blind private investigator. 
- The Police Chief: The chief of police and The Detective's friend. A man with absolute, unflinching moral principles.

- The Client: A seemingly sweet and innocent girl. She solicits The Detective after her fiance has gone missing.

- The Secretary: The secretary of The Detectives private investigation firm. She will serve as a hint system, any time the player finds a phone, they can call the secretary to get more info on the current puzzle they are facing.

- The Crime Boss: The local crime boss and proprietor of the night club. He will serve as the main antagonist.

\section{Gameplay Elements}

- Secretary hints: If the player ever finds a phone, they can use it to call The Secretary and get hints on the current problem they are trying to solve. This will come either in the form of new information that has been given to The Secretary from a third party, or asking The Secretary for advice.

- White Cane: The player has a 'white cane', these are the canes that visually impaired people use to navigate spaces. At any time the player can press a button on their controller to activate the white cane. This will make a sound depending on what is in front of the player. If the space in front of the player is empty, a certain tapping sound will be made. If the space in front of the player is occupied, then a different tapping sound will be made

- Examine: The player can examine objects in the environment, this will give a description of the object and any objects that may be on top of, or inside the object. 


\section{User Interface}

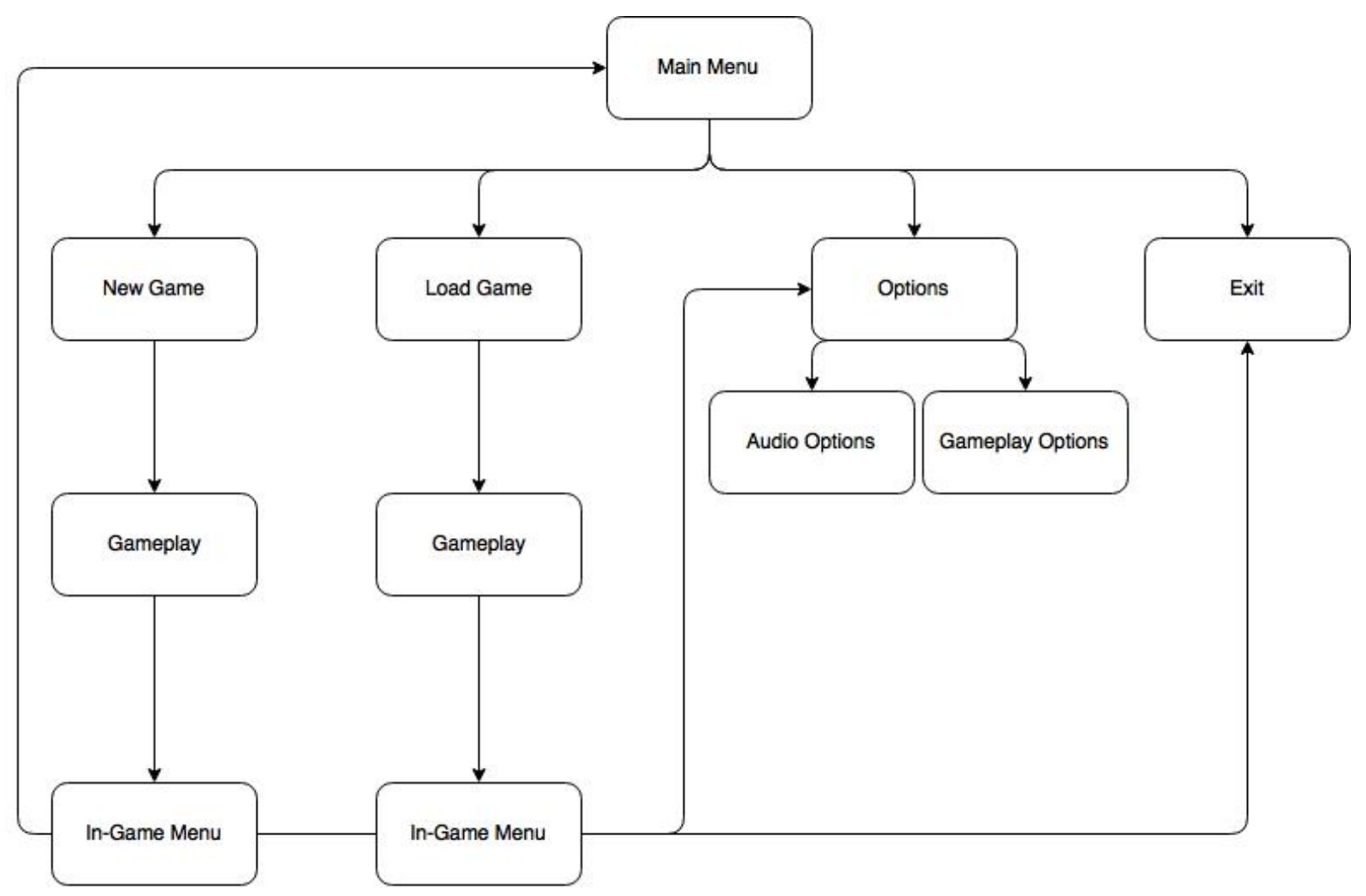

\section{Functional Requirements}

Main Menu: Presents an audio readout of each menu item when selected, simple cycle through. Ambient yet compelling music that conveys the tone of the game.

New Game/Introduction: Plays a short introductory audio clip, setting up the world and premise of the game, then moves into gameplay.

Load Game: This will load an existing saved game.

Audio/Gameplay Options: Opens a menu screen where the player can edit the the options of the game. Volume, control sensitivity, etc. 
Exit: This will exit to desktop

Gameplay: This is where the game takes place

\section{Risks/Challenges}

- Mature Themes: The noir style lends itself to darker and more mature themes. This will significantly limit the potential player base.

- Communicating Information: There are several pieces of information that the player may need that will be difficult to convey. 


\section{Appendix II}

Appendix 2.1 - Participant Consent form

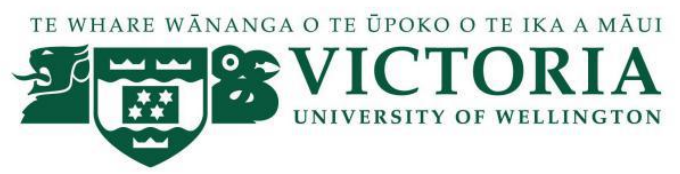

\section{Turning a Blind Eye: An Exploration of Non-Visual Game Design CONSENT TO INTERVIEW}

This consent form will be held for 3 years.

Researcher: Hunter Mulder, School of Design, Victoria University of Wellington

- I have read the Information Sheet and the project has been explained to me. My questions have been answered to my satisfaction. I understand that I can ask further questions at any time.

- I agree to take part in the testing of prototype computer games, and an audio recorded interview held under the supervision of a Blind and Low Vision Education Network NZ staff member

I understand that:

- I may withdraw from this study at any point before 30th March 2017, without giving any reason, and any information that I have provided will be returned to me or destroyed.

- $\quad$ The information I have provided will be destroyed 3 years after the research is finished.

- $\quad$ Any information I provide will be kept confidential to the researcher and the supervisor. I understand that the results will be used for a masters report and a summary of the results may be used in academic reports and/or presented at conferences.

- My name will not be used in reports, nor will any information that would identify me.

I would like to receive a copy of the final report and have added my Yes No email address below.

Signature of participant:

Name of participant: 
Date:

Contact details: 


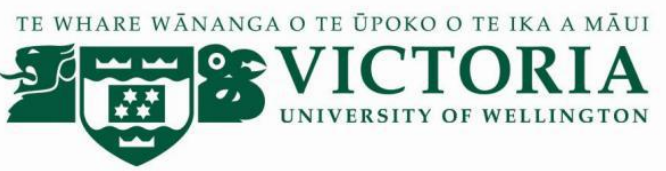

\title{
Turning a Blind Eye: An Exploration of Non-Visual Game Design
}

\author{
INFORMATION SHEET FOR PARTICIPANTS
}

Thank you for your interest in this project. Please read this information before deciding whether or not to take part. If you decide to participate, thank you. If you decide not to take part, thank you for considering my request. You must be aged 16 or over to take part.

Please note, audio versions of all these forms are available upon request.

\section{Who am I?}

My name is Hunter Mulder and I am a masters student in Masters of Design Innovation at Victoria University of Wellington. This research project is work towards my thesis.

\section{What is the aim of the project?}

This project aims to explore the effects of designing an audio-only computer game with virtual reality technologies. This research has been approved by the Victoria University of Wellington Human Ethics Committee 0000023891.

\section{How can you help?}

If you agree to take part I would like you to play a prototype of a computer game I have created specifically targeted towards visually impaired people. You would test this game alongside a group of your peers and be accompanied by a teacher from the Blind and Low Vision Education Network NZ. This would take place in a classroom at the Blind and Low Vision Education Network NZ School in Kelburn. One person will play the prototype at a time, once they have completed the experience, 
I will ask them a few questions about the prototype whilst the next person plays through the prototype. This will continue until every person has played the prototype and answered the questions. The process will take approximately an hour for the entire group. I will audio record the interview and write it up later.

There will also be a short interview that will take place on a date prior to the playtest and main interview. This short interview will be conducted in the same way as the post-playtest interview however will only take around 10 minutes for the entire group.

You can stop playing the game and/or the interview at any time, without giving a reason. You can withdraw from the study by contacting myself or your teacher at any point before 30th March 2017. If you withdraw, the information you provided will be destroyed or returned to you.

\section{What will happen to the information you give?}

This research is confidential. This means that the researchers named below will be aware of your identity but the research data will be aggregated and your identity will not be disclosed in any reports, presentations, or public documentation.

Only my supervisors and I will read the notes or transcript of the interview. The interview and any recordings will be kept securely and destroyed 3 years after the research ends.

\section{What will the project produce?}

The information from my research will be used in my thesis and potentially in academic reports and/or at conferences.

\section{If you accept this invitation, what are your rights as a research participant?}

You do not have to accept this invitation if you don't want to. If you do decide to participate, you have the right to:

- choose to stop playing the game at any time; 
-choose not to answer any question;

-ask for the recorder to be turned off at any time during the interview;

- withdraw from the study before 30th March 2017;

-ask any questions about the study at any time;

- be able to read any reports of this research by emailing the researcher to request a copy.

If you have any questions or problems, who can you contact?

If you have any questions, either now or in the future, please feel free to contact either:

\section{Student:}

Name: Hunter Mulder

University email address:

mulderhunt@myvuw.ac.nz
Supervisor:

Name: Byron Mallett

Role: Lecturer

School: Victoria School of Design

Phone: 044636229

byron.mallett@vuw.ac.nz

\section{Human Ethics Committee information}

If you have any concerns about the ethical conduct of the research you may contact the Victoria University HEC Convener: Associate Professor Susan Corbett. Email susan.corbett@vuw.ac.nz or telephone +64-4-463 5480 . 


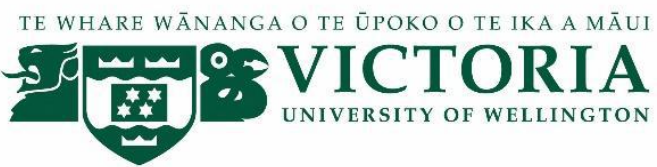

\title{
Turning a Blind Eye: An Exploration of Non-Visual Game Design
}

\author{
Preliminary Interview
}

1. What video games have you played before?

2. If you have played video games before, what did you most enjoy about the experience?

3. What did you not enjoy about the experience?

4. Are there any features you wish those games had that would make the experience more enjoyable?

5. What genres or styles of game would you like to play that are not currently accessible to you?

6. What kind of hardware devices have you used to interact with games or computers?

7. If they were available, what hardware devices would you like to use to interact with games? 


\section{Turning a Blind Eye: An Exploration of Non-Visual Game Design}

\section{Questions}

1. What was your favourite part of the game?

2. What was your least favourite part of the game?

3. Was the game difficulty satisfactory, too easy or too difficult?

4. If you were to suggest one change to the game, what would it be?

5. Could you play this game again without having the rules explained?

6. Was the reason you won or lost the game clearly communicated?

7. Would you play this game again? 
MEMORANDUM

\begin{tabular}{l|l}
\hline TO & Hunter Mulder \\
\hline COPY TO & Byron Mallett \\
\hline FROM & AProf Susan Corbett, Convener, Human Ethics Committee \\
\hline \multicolumn{2}{|l}{} \\
\hline DATE & 21 February 2017 \\
\hline PAGES & 1 \\
\hline
\end{tabular}

ndix

Ethic

SUBJECT

Ethics Approval: 23891

Turning a Blind Eye: An Exploration of Non-Visual Games

Thank you for your application for ethical approval, which has now been considered by the Standing Committee of the Human Ethics Committee.

Your application has been approved from the above date and this approval continues until 1 July 2017. If your data collection is not completed by this date you should apply to the Human Ethics Committee for an extension to this approval.

Best wishes with the research

Kind regards

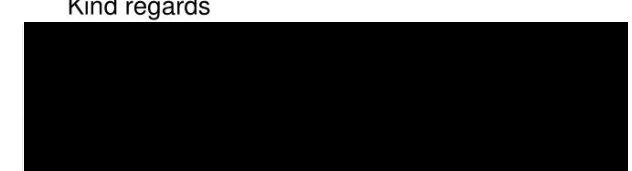

Susan Corbett

Convener, Victoria University Human Ethics Committee 


\begin{tabular}{|l|l|}
\hline Committee Members Present: & $\begin{array}{l}\text { H Philips; J Budd; E Gilmour: B Whitely: K } \\
\text { Stobbs; G Good. }\end{array}$ \\
\hline Name of Researcher: & Hunter Mulder \\
\hline Research: Turning a blind Eye: An Exploration of Non-Visual Game Design
\end{tabular}

\section{Reflections:}

Overall this project has merit and is very relevant to the students of BLENNZ.

Relationship with BLENNZ staff in Wellington will be essential for the effective progression of this project.

General:

Suggestions and requests

\section{Purpose}

May be helpful if you were to clarify the aim of your research - effects of the game on what? Is it more around developing a non-visual reality game and considering if students who are blind or have low vision can play and enjoy the game.

It may be richer if you could provide more explanation around the need for this type of research and how it is important to students who are blind or have low vision.

Recording

Please clarify, are interviews and observations audio-taped or just the interviews.

Usually records of interviews are provided to the participant, recommend that they are given a copy and invited to feedback, as they may provide clarity / additional information.

\section{Sessions}

Please confirm the duration of the sessions, is it that a session will last 20-30 mins and within that the game will take $5-10$ mins to play?

\section{Documentation}

Check documentation re format required:

- Electronic

- Large print

- Braille.

Typo: the word 'masters' needs to be amended to Masters

On the consent form need to change dates and edit 'Masters' word.

In future when sending applications through consider there accessibility to the end user, the screen captured documents were not visible to one of our members.

\section{Consents}


Would suggest that parent information sheet is provided and depending on age will require a parent consent form.

Need to acknowledge that students will know each other and could be identified to one another.

\section{Cohort}

Will need to confirm cohort:

- Currently not specifically defined - blind / low vision.

- Are numbers available in this area?

Need to confirm numbers re cohort available in Wellington.

\section{Recommendation:}

BLENNZ Research Ethics Committee support this research application with the provisos:

- that this is done in partnership with members of the BLENNZ Wellington based team and

- that parents are fully informed and

- appropriate consents are in place prior to the session taking place.

Please make contact with BLENNZ Wellington team members including:

- cathy.west@blennz.school.nz and

- karen.gilligan@blennz.school.nz

who will work with you to identify participants.

They will support you in the consent process and work with you to identify a suitable venue and time for this to take place, providing practical support to ensure learner access and wellbeing is supported.

\section{Karen Stobbs}

Principal

(on behalf of the BLENNZ Ethics Committee) 


\section{Bibliography}

Blesser, B. (2007). Spaces speak, are you listening? : experiencing aural architecture / Barry Blesser and Linda-Ruth Salter. (L.-R. Salter \& I. ebrary, Eds.). Cambridge, Mass.: Cambridge, Mass. : MIT Press.

The Blind Spot. (2014, June 9). Video Games For The Blind! [Video file]. Retrieved from: https://www.youtube.com/watch?v=cZkR0smB9Jw\&feature=youtu.be

Chion, M., Gorbman, C., \& Murch, W. (1994). Audio-vision: Sound on screen. New York: Columbia University Press.

Csikszentmihalyi, M. (1990). Flow: The psychology of optimal experience. New York: Harper \& Row.

Davis, A. (2008). OPERATIONAL PROTOTYPING: A NEW APPROACH. IEEE, 9(5), 70 -78. http://dx.doi.org/10.1109/52.156899

Edwon Studio (2016). VR Infinite Gesture [Computer Software]

Emmerson, S. (1999). Aural Landscape: Musical Space. London: City University.

Entertainment Software Association. (2015). Retrieved January 14, 2017, from http://www.theesa.com/wp-content/uploads/2015/04/ESA-Essential-Facts-2015.pdf

Fabricatore, C. Nussbaum, M. \& Rosas, R. (2002) Playability in Action Videogames: A Qualitative Design Model, Human-Computer Interaction, 17:4, 311-368

Friberg, J. Gardenfors, D. (2004). Audio Games: New Perspectives on Game Audio.

Fullerton, T., Hoffman, S., \& Swain, C. (2008). Game design workshop: designing, prototyping, and playtesting games. San Francisco, CA: CMP Books. 
Heinlein, R. (1961). Stranger in a strange land. New York :Ace Books,

Hunicke, R. Leblanc, M. Zubek, R. (2004). MDA: A formal approach to game design and game research.

Ihde, D. (2007). Listening and voice: Phenomenologies of sound. Albany: State University of New York Press.

Iwaniuk, A. Nelson, E. Pellis, s. (2001). Do big-brained animals play more? Comparative analyses of play and relative brain size in mammals. Journal of Comparative Psychology.

Jacobson, W. H. (1993). The art and science of teaching orientation and mobility to persons with visual impairments. New York: AFB Press.

Kendall, G. S., \& Ardila, M. (2008). The Artistic Play of Spatial Organization: Spatial Attributes , Scene Analysis and Auditory Spatial Schemata. In S. Y. and K. J. Richard

Koster, R. (2005). A theory of fun for game design. Scottsdale, AZ: Paraglyph Press.

Lahav, O. (2014). Virtual reality as orientation and mobility aid for blind people. Israel: Tel Aviv University.

Zhu, M. Zhao, F. Fang, X. Moser, C. (2017) Developing Playability Heuristics Based on Nouns and Adjectives from Online Game Reviews, International Journal of Human-Computer Interaction

Oldenburg, A. (2013). Sonic Mechanics: Audio as Gameplay. International Journal of Computer Game Research

Oliveira, A.F.S., Rossi, A.O., Silva, L.F.R. et al. J Ethol (2010). Play behaviour in nonhuman animals and the animal welfare issue. 
Rebernik, M. (n.d). Idea Evaluation Methods and Techniques. Retreived from http://www.innosupport.net/index.php?id=6038\&tx_mmforum_pi1[action]=get_attachment\&tx_mm forum_pi1 [attachment] $=4088$.

Ries, e. (2009). Minimum Viable Product: A Guide

Rumsey, F. (2001). Spatial audio. Oxford; Boston: Focal Press.

Sánchez, J. L. G., Simarro, F. M., Zea, N. P., \& Vela, F. L. G. (2009). Playability as extension of quality in use in computer games. In Proceedings of 2nd International Workshop on the Interplay Between Usability Evaluation and Software Development (I-USED), paper number 6, Uppsala, Sweden.

Seki, Y. Sato, T. (2011). A Training System of Orientation and Mobility for Blind People Using Acoustic Virtual Reality. IEEE Transactions on Neural Systems and Rehabilitation Engineering.

Serafin, S. Serafin, G. (2004). Sound Design to Enhance Presence in Photorealistic Virtual Reality.

Smalley, D. (2007). Space-form and the acousmatic image. Organised Sound, 12(01), 35. http://doi.org/10.1017/S1355771807001665

Smalley, D. (1996). The listening imagination: Listening in the electroacoustic era. Contemporary Music Review, 13(2), 37-41.

Sterne, J. (2012). The sound studies reader. New York: Routledge.

Sumikawa, D.A. (1985). Guidelines for the integration of audio cues into computer user interfaces. California: Lawrence Livermore National Lab.

Torgue, J.-F. A. and H. (2006). Sonic experience: a guide to everyday sounds. Montreal; Ithaca: McGill-Queen's University Press. 
"Visual Impairment and Blindness." World Health Organization. World Health Organization, n.d. Web. 16 August 2016.

"Population." United Nations. United Nations, n.d. Web. 16 August 2016.

Sounds used in game:

https://www.freesound.org/people/aerror/sounds/350749/

https://www.freesound.org/people/jorickhoofd/sounds/169555/

https://www.freesound.org/people/RSilveira_88/sounds/216244/

https://www.freesound.org/people/Timbre/sounds/221683/

https://www.freesound.org/people/InspectorJ/sounds/352513/

https://freesound.org/people/freefire66/sounds/175951/

https://freesound.org/people/LiamG_SFX/sounds/323083/

https://freesound.org/people/ztrees1/sounds/134935/

https://www.freesound.org/people/ebcrosby/sounds/332976/

https://www.freesound.org/people/miklovan/sounds/198278/

https://www.freesound.org/people/thanvannispen/sounds/9667/

https://www.freesound.org/people/rubberduckie/sounds/219836/

https://freesound.org/people/beejeeb1314/sounds/197743/

https://freesound.org/people/Snapper4298/sounds/166707/

https://www.jamendo.com/album/105230/celtic-moods-and-irish-folk?language=en 